\title{
Analysing non-coaxial folding effects in the Small Circle Intersection method
}

\author{
P. Calvín ${ }^{\oplus, 1}$ E.L. Pueyo ${ }^{\oplus},{ }^{2,3}$ M.J. Ramón, ${ }^{2,3}$ A.M. Casas-Sainz ${ }^{\oplus 3,4}$ and J.J. Villalaín ${ }^{\oplus 1}$ \\ ${ }^{1}$ Departamento de Física, Universidad de Burgos, Av/ Cantabria s/n, 09006 Burgos, Spain.E-mail: calvinballester@gmail.com \\ ${ }^{2}$ Instituto Geológico y Minero de España (IGME)- Unidad de Zaragoza, Manuel Lasala 44, 50006 Zaragoza, Spain \\ ${ }^{3}$ Unidad Asociada en Ciencias de la Tierra IGME/Universidad de Zaragoza, Spain \\ ${ }^{4}$ Geotransfer Research Group (IUCA), Universidad de Zaragoza, c/ Pedro Cerbuna s/n, 50009 Zaragoza, Spain
}

Accepted 2020 May 1. Received 2020 April 29; in original form 2020 January 16

\begin{abstract}
SUMMAR Y
The Small Circle (SC) tools analyse the stereographic tracks (small circles) followed by the palaeomagnetic vectors during folding processes. Working with interfolding and synfolding remagnetizations, the Small Circle Intersection (SCI) method allows finding the best solution of grouping that should correspond with the remagnetization direction. Once this is known, it is possible to determine the magnetization age as well as the degree of bed tilting at this moment. The SC tools are based on some assumptions, among which the coaxiality between the different deformation events is the one addressed in this work (i.e. absence of vertical axis rotations, VARs, or differential horizontal axis rotations, dHARs). This assumption is based on the necessity of knowing the rotation axis for folding after the acquisition of the remagnetization, and $\mathrm{SC}$ tools consider the bedding strike as this axis, something that is only accomplished under coaxial folding. In order to explore how non-coaxiality affects the solutions derived from the SC methods, we first (i) identify the variables that control these errors through simple models that only consider two theoretical palaeomagnetic sites, after that it is possible (ii) to derive the mathematical relationships between them. Finally, we (iii) simulate errors derived from the use of SC tools using a population of 30 palaeomagnetic sites recreating different possible scenarios with VARs and dHARs in nature.
\end{abstract}

Key words: Palaeomagnetism; Remagnetization.

\section{INTRODUCTION}

Remagnetizations have a higher degree of uncertainty than primary palaeomagnetic vectors for calculating vertical axis rotations. This statement is based on two main facts: (i) it is more difficult to set the palaeomagnetic reference direction in remagnetizations than in primary records, (ii) the palaeo-horizontal at the time of remagnetization is uncertain (this reduces the usefulness of palaeomagnetic vectors as a 3-D indicator). Both factors play against the reliability of the Apparent Polar Wander Path (APWP) poles, Vertical Axis Rotations (VARs), etc., estimated from remagnetized directions.

The aforementioned problems can be partially overcome using the Small Circle (SC) tools (McClelland-Brown 1983; Surmont et al. 1990; Villalaín et al. 1992, 2003, 2016; Shipunov 1997; Waldhör 1999; Enkin et al. 2000; Henry et al. 2004; Waldhör \& Appel 2006; Calvín et al. 2017a), which are especially useful when working with interfolding remagnetizations (those acquired between two distinct folding stages). In particular, SC tools allow for (i) overcoming the limitations of the classic fold test (e.g. Lewchuk et al. 2003; Meijers et al. 2011), (ii) a better determination of the remagnetization direction (e.g. Shipunov 1997) and therefore (iii) a more reliable dating derived from APWP comparisons (e.g., Enkin et al. 2000; Henry et al. 2001) and finally (iv) estimating a trustworthy attitude of beds (palaeodips) at the remagnetization time (see Villalaín et al. 2016; for a review). These approaches can be used to reconstruct the palaeo-geometry of sedimentary basins at the pre-inversion stage (e.g. Torres-López et al. 2016, 2018), to differentiate deformation events occurred under different tectonic phases (Smith et al. 2006) or for the relative dating of geological structures (Calvín et al. 2017b). However, some starting assumptions are implicit when working with SC tools:

(1) The isochrony of the magnetization process at geological scale. This may be accepted for primary components but more difficult to assume in interfolding, synfolding or post-folding processes since remagnetization can be related to fluid circulation, burial, and other long-lasting processes (e.g. Elmore et al. 2012).

(2) The interfolding or synfoldingcharacter of the remagnetizationis real and not an artefact due to, for example, overlapping between different palaeomagnetic components (Rodríguez-Pintó et al. 2013) or internal deformation of a prefolding palaeomagnetic component (e.g. Van der Pluijm 1987; Stamatakos \& Kodama 1991; 
Borradaile 1997; see also an overview of causes of apparent synfolding in Pueyo et al. 2016).

(3) The natural along-strike scattering of bedding attitude in orogenicregions. Without this scatter the SC method does not work because this factor governs the likelihood of a significant solution. However, Waldhör \& Appel (2006) have demonstrated the occurrence of such scattering compiling more than 1000 palaeomagnetic and bedding data from several orogenic systems.

(4) Pre- and post-remagnetizationdeformation must be coaxial. This is the very essence of the SC method (but also of a substantial proportion of restoration methods in palaeomagnetism). The SCs are defined by the in situ palaeomagnetic direction and the bedding strike. Each SC is the path followed by a palaeomagnetic direction when it is rotated around the bedding strike (Fig. 1a); in absence of rotations axes other than the strike, each SC limits the possible orientation of the palaeomagnetic direction in previous stages. Then, a set of palaeomagnetic sites affected by the same interfolding or synfolding remagnetization must share this palaeomagnetic direction. If they were differentially folded in the post-remagnetization stage, they will show different in situ palaeomagnetic directions (Fig. 1b). However, the SCs of all sites must intersect in a common palaeomagnetic (remagnetization) direction (Fig. 1b, see Calvín et al. 2017a; for review). Nevertheless, this is only true if SCs represent the actual path followed by the palaeomagnetic direction during deformation, and if all analysed sites share the same remagnetization direction (isochrony of the magnetization process).

Both coaxiality and non-coaxiality are common in nature in either inverted basins or fold-and-thrust belts. Non-coaxial structures are generated by superposed folding/tilting where successive deformation stages display different horizontal axes of rotation (dHARs, e.g. Ramsay \& Huber 1987; Pueyo et al. 2003; Simón 2004; Baidder et al. 2016; Deng et al. 2016). Non-coaxiality can also derive from coaxial processes in which vertical axis rotations (VARs) have acted at intermediate stages (e.g. MacDonald 1980; McCaig \& McClelland 1992; Allerton 1994, 1998; Pueyo et al. 2004; Soto et al. 2006; Sussman et al. 2012). If these processes take place after the remagnetization acquisition, they will be responsible for a malfunctioning of the SC tools. Under this scenario, the actual bedding strike is not the (only) rotation axis whereby the beds had been deformed and therefore the SCs do not represent the possible positions of the palaeomagnetic directions (Pueyo et al. 2016).

Some works using the SC tools have confronted the occurrence of VARs (Waldhör 1999; Henry et al. 2004). From different mathematical approaches, these authors have proposed a similar concept based on the observation of the differences between divergent small circles and the main intersection cluster on one side and the expected inclination of the remagnetization on the other. This approach may return a satisfactory analysis but needs to assume a known remagnetization direction. Other authors (Antolín et al. 2012) have done qualitative analyses of the SC taking into consideration structural data; for example grouping the sites following structural criteria (different trends). In any case, it is clear that the likely occurrence of VAR will introduce noise and uncertainty in the standard application of the SC tools. Moreover, there are not works analysing the effect of dHARs in the SC method.

This paper focuses on the effect of non-coaxiality (s.1.), either resulting from dHAR or VAR, in the calculation of the remagnetization direction and in the reconstruction of the palaeodips (i.e. the dips of bedding at the remagnetization time) when using the $\mathrm{SC}$ tools. We approach the problem considering an interfolding remagnetization acquired between two different deformational events (i.e. bracketed between two deformational stages having a tectonic quiescence period in-between). Note that we use the term 'interfolding' to distinguish it from 'synfolding' that can be interpreted as a rather continuous event during which rocks are remagnetized). This is for example the case of several Mesozoic sedimentary basins analysed in the Western Tethyan margin (e.g. Casas et al. 2009; Soto et al. 2011; Torres-López et al. 2014; García-Lasanta et al. 2017). However, SC tools can be also useful working with synfolding remagnetizations (e.g. McClelland-Brown 1983; Enkin et al. 2003; Lewchuk et al. 2003); although in this case the acquisition of the remagnetization can be progressive in the different palaeomagnetic sites following the development of the deformation, the initial assumptions can be also fulfilled. For that, we firstly explore the errors produced by VARs using the SCs tools from a conceptual point of view: we will identify the key variables and we will propose the mathematical equations that govern the errors. After that, errors in the calculated remagnetization direction and in the palaeodips are analysed in dHARs and VARs scenarios through synthetic models that illustrate possible real situations. Finally, we propose and discuss a novel approach than considers the occurrence of VARs.

\section{NATURAL STRIKE DISPERSION VERSUS VAR OCCURRENCE}

A natural scattering in the strike distribution is needed for the application of the SC method (Waldhör 1999; Henry et al. 2004). Additionally, and to a variable extent, VARs are common in most fold and thrust belts. VAR are most commonly related to differential shortening (McCaig \& McClelland 1992; Allerton 1994, 1998; Pueyo et al. 2004; Soto et al. 2006; Sussman et al. 2012). At small scale, non-cylindrical geometries, some obliquity patterns, non-coaxial deformation, inherited anisotropies, superposed folding, etc., may cause local, variable differential VARs, which cannot therefore be neglected. Local differential rotations are independent from large-scale regional patterns of rotations commonly governed by orogen-scale factors. Accommodation to plate boundaries (i.e. indentations) and differential movements of basement nappes, etc., can be responsible for large-scale gradients of shortening that will additionally have an imprint in the palaeomagnetic vectors in large areas.

An analysis on the VAR distribution similar to the one on strike scattering carried out by Waldhör \& Apple (2006) to justify the applicability of SC tools will help to illustrate why the users of the SC method should be careful with VARs. The Pyrenean palaeomagnetic database (López et al. 2008) has adopted and implemented data models (Pueyo et al. 2017) from standard databases like MAGIC (Tauxe et al. 2016). It currently comprises more than 2500 palaeomagnetic sites (with standard information and hundreds of metadata) and allows evaluating the natural strike variability, the occurrence of VARs and the scattering of strikes after the subtraction of the VAR magnitude (Fig. 2). In the Pyrenees, the actual strike distribution is bimodal (Fig. 2a), reflecting the large proportion of oblique structures in the mountain belt (Pueyo et al. 2003; Sussman et al. 2004; Mochales et al. 2012; Muñoz et al. 2013; RodríguezPintó et al. 2016 among others). The main maximum is the so-called 'Pyrenean trend' $\left(\approx \mathrm{N} 105^{\circ} \mathrm{E}\right)$ and the other, less important, belongs to the 'N-S' (oblique) structures. The VAR distribution is symmetric but off centre (Fig. 2b); it is worth mentioning that the absolute VARs display a significant mean value, $27.4^{\circ}\left(\sigma= \pm 20.7^{\circ}\right.$, Fig. 2c $)$ and almost 70 per cent of the studied sites displayed significant VAR $\left(>15^{\circ}\right)$. Therefore, VARs could be never obviated if the SCI method 

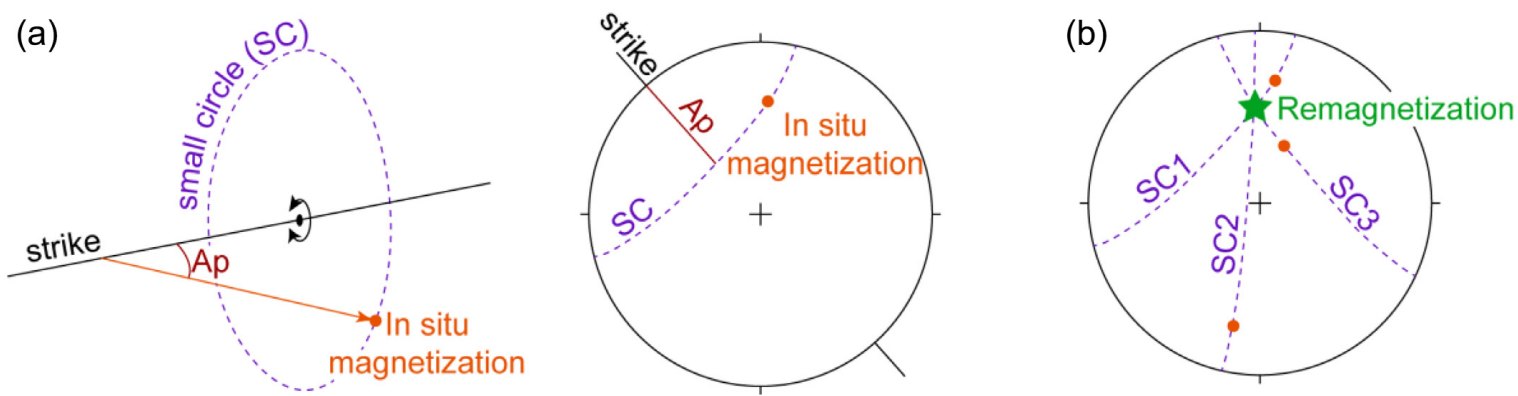

Figure 1. Fundamentals of the SCI method: (a) each small circle is the path followed by the in situ magnetization when it is rotated around the bedding strike. 3-D view (left-hand panel) and equal area projection (right-hand panel). (b) Working with a set of palaeomagnetic sites that record the same remagnetization, and in absence of non-coaxial rotation, the small circles must intersect in the remagnetization direction.

(a) Strike distribution

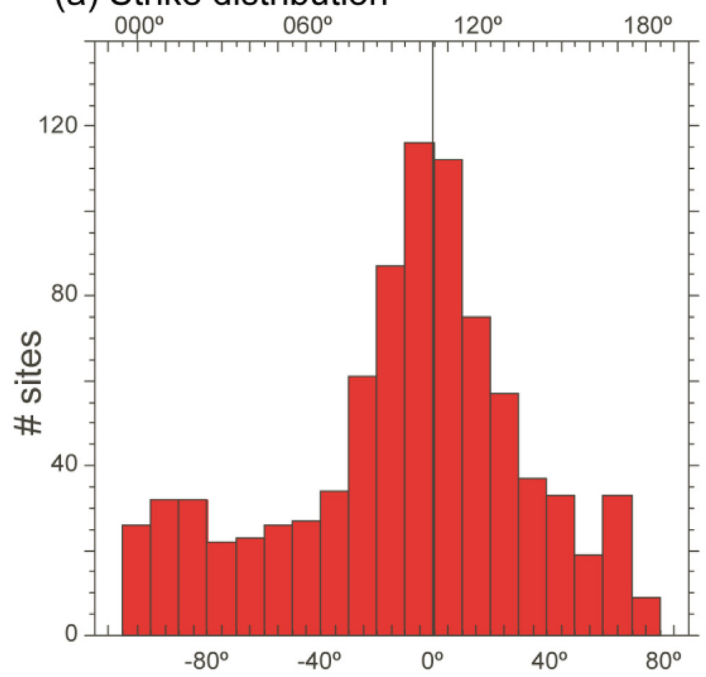

(c) VAR distribution (absolute magnitude; ${ }^{\circ}$ )

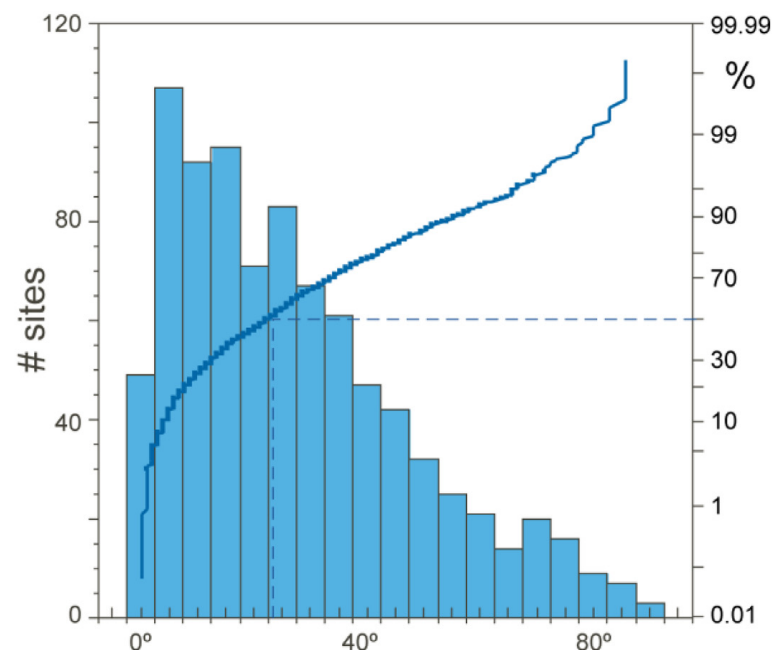

(b) VAR distributioon

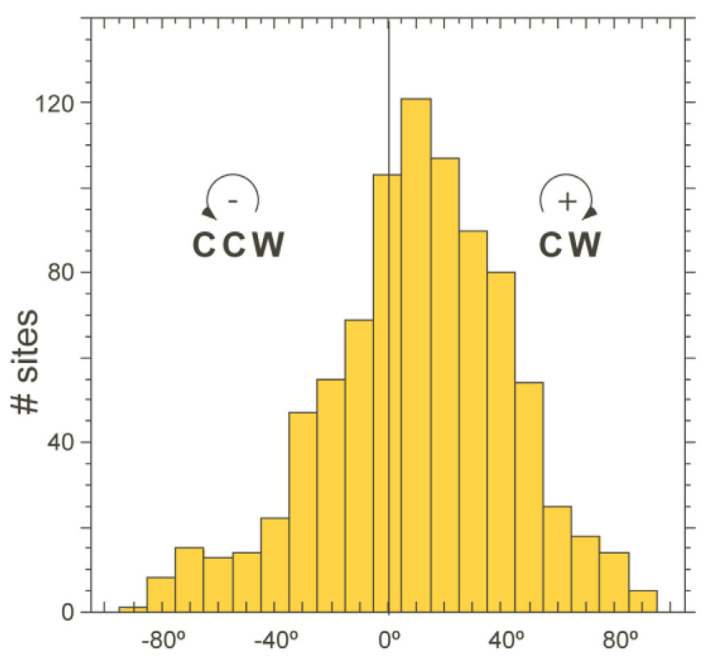

(d) Strike corrected [-VAR]

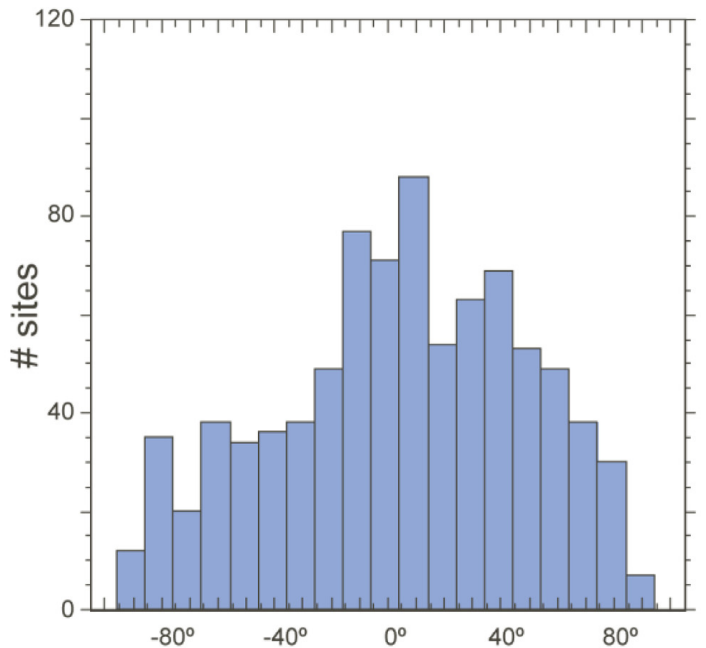

Figure 2. Natural variability of strikes and VARs; an example from the Pyrenean palaeomagnetic database. More than 2500 palaeomagnetic and bedding data processed after Ramón (2013), see also recent overviews by Oliva-Urcia \& Pueyo (2019) and Pueyo et al. (2020). (a) Distribution of bedding strike in geographic coordinate system. (b) Distribution of VAR, differentiating clockwise (CW) and counter clockwise (CCW). (c) Distribution of VAR absolute magnitude. (d) The strike distribution after the restoration of VAR (site by site). 
would be applied in the Pyrenees. Nonetheless, the natural variability on the strike (after correcting the VAR effect) is still high enough to guarantee the applicability of the SC tools (Fig. 2d).

\section{UNCERTAINTY CAUSED BY VARS: SIMPLEST CASE WITH TWO LIMBS}

Consider a simple fold with two limbs (Fig. 3a) that has undergone an interfolding remagnetization event, and was subsequently refolded coaxially, increasing $30^{\circ}$ the dip of each limb after the blocking of the new component (Fig. 3b). In this ideal case, the SC method accurately provides the remagnetization direction (black star) as well as the palaeodips of the beds at the remagnetization time. However, the occurrence of differential rotations between the limbs (Figs 3c and d) will yield erroneous estimations in the SC methods. Coming back to our example and in the case of clockwise (CW) VAR (Fig. 3c), the SC intersection returns (small red stars) almost the expected direction (black star), but just by chance. When counterclockwise (CCW) VAR takes place (Fig. 3d) the SC solution is meaningless $\left(-55^{\circ} \mathrm{VAR}\right)$, or even some small circles for variable amounts of VAR (from -20 to $-40^{\circ}$, red SC in Fig. 3d) do not intersect the SC from the other limb (the unrotated one). Therefore, the presence of VAR may deflect significantly the SC result, both in declination and inclination.

\subsection{Definition of variables}

Initially, we have performed models and examples considering two limbs, A and B, undergoing variable magnitudes and senses of differential VARs between them. The main goal of these simplistic examples is to assess the influence of the different variables in the magnitude of uncertainty and errors. Several variables have to be initially considered (Fig. 4):

(1) Orientation of the remagnetization vector defined by its declination and inclination. Inclination $(\tau)$ has been especially taken into account in the following examples.

(2) Obliquity $(\alpha)$ measured in the horizontal plane $(\mathrm{CW}$ is + and $\mathrm{CCW}-$ ) between the closest bedding strike and the declination of the palaeomagnetic reference (remagnetization).

(3) Primary non-coaxiality $(\Omega)$. The angle between the two considered beds measured in the horizontal plane $(\mathrm{CW}$ is + and $\mathrm{CCW}$ -) allows the application of the SC methods.

(4) VAR angle undergone by a bed after the remagnetization. To simplify, we have considered the differential rotation just in one of the beds (or alternatively in the other but not simultaneously). Again, CW is + and CCW -.

(5) Once the VAR has taken place in one limb (Fig. 4c), the stereographic region delimited between the expected results (with an error both in declination and inclination) is defined as the uncertainty region.

\subsection{Characterization of errors and uncertainty regions}

In the first set of models (Fig. 5) we have kept constant $\alpha\left(0^{\circ}\right)$ and $\Omega$ $\left(30^{\circ}\right)$ and we have modified the inclination $(\tau)$ and the VAR angle. In turn, we considered the same fold pattern with five different inclinations $\left(20^{\circ} \mathrm{red}, 30^{\circ}, 40^{\circ}, 50^{\circ}\right.$ and $60^{\circ}$ blue). For the VAR, we start at $0^{\circ}$ and then we apply $15^{\circ}$ increments up to $60^{\circ}$ (both $\mathrm{CW}$ and $\mathrm{CCW}$ ). We analyse four different situations to observe the effect on the uncertainty region; one limb rotates $\mathrm{CW}$ or $\mathrm{CCW}$ while the other is kept fixed, and then in reverse order. The uncertainty regions (coloured as a function of $\tau$ ) were defined joining the expected results (the rotated and unrotated) for a given $\tau$, with the actual ones. Of course, the SCI solution for VAR $=0^{\circ}$ returns the expected palaeomagnetic direction and would allow to perform an accurate reconstruction of the palaeodips (small stereonet in Fig. 5).

Considering VAR $\neq 0^{\circ}$, the first remarkable observation is the total absence of symmetry in the four study cases (variable and opposite rotations of one limb or the other). On the other side, one may initially expect than the SCI solution would yield an intermediate direction between the unrotated and the rotated references, but intersections may lie far away from it and even the magnitudes of errors (both in declination and inclination) are strongly dependent upon the attitude of planes, vectors and VAR angles.

Common features for the shown cases are the following: (1) the larger the magnitude of VARs, the greater the uncertainty region (and the individual errors), (2) the steeper the inclination of the remagnetization, the smaller the expected error and the uncertainty region. (3) VAR may even cause the absence of intersections between SC.

In the following test (Fig. 6), we vary the angle between the remagnetization vector and the bedding strike $(\alpha)\left(\alpha=45^{\circ}, 90^{\circ}\right.$, $135^{\circ} ; \alpha=0^{\circ}$ can be seen in Fig. 5), which has also a critical influence in the result of the SCI method if VARs are present. Again, we have modelled these cases imparting a constant VAR magnitude $\left( \pm 30^{\circ}\right)$ in only one limb to isolate the uncertainty (both senses of rotation separately). Then we increased the VAR magnitude $\left( \pm 30^{\circ}\right)$ in the other limb. The number of inclinations modelled and the increments of the VAR angle was reduced for the sake of simplicity. The primary non-coaxiality $(\Omega)$ between both limbs was kept constant. Again, in all these cases there exists a great asymmetry in the errors and in the uncertainty regions.

The increase of $\alpha$ (for a similar situation, same amount of VAR in the same limb; same column in Fig. 6) produces variable changes in the uncertainty regions; the larger domains of uncertainty are found when $\alpha=90^{\circ}$. One remarkable observation refers to the change of the original $\Omega$ (primary non-coaxiality) after the VAR has taken place; when this angle is reduced (or even changed its sense) the uncertainty regions are much larger (e.g. limb SE rotates CW and limb NW rotates CCW for $\alpha=45^{\circ}$ in the first row). The opposite happens when $\Omega$ increases.

Therefore, these simple models emphasize the impact of VARs in the SCI result; moderate magnitudes of VAR may significantly change the derived remagnetization direction (in both inclination and declination). Obviously, the occurrence of VARs will also modify the estimated palaeodips in palinspastic reconstructions.

\subsection{Mathematical modelling of errors}

After evaluating the impact of VARs in the SC method in a graphic way, we proceed to quantify the errors in declination and inclination caused by different initial assumptions. For that, we now describe the equations that govern this simple case of a two-limb fold.

Starting from two sites (S01 and S02) located in both limbs of a fold showing strike $s_{n}$ and dip $d_{0}$, and a remagnetization pmag0, a second stage of folding with a coaxial tilting angle $(\Omega)$ modifies these palaeomagnetic values to pmag1, pmag2 and $\mathrm{d}_{1}$. Finally, the vertical axis rotation $\mathrm{VAR}=\beta$ is produced in one of the limbs (see Appendix A).

The expected palaeomagnetic result $\left(\mathrm{DEC}^{*}, \mathrm{INC}^{*}\right)$ will be the crossing point between the two resulting small circles SC1 and 
(a) Remagnetization time

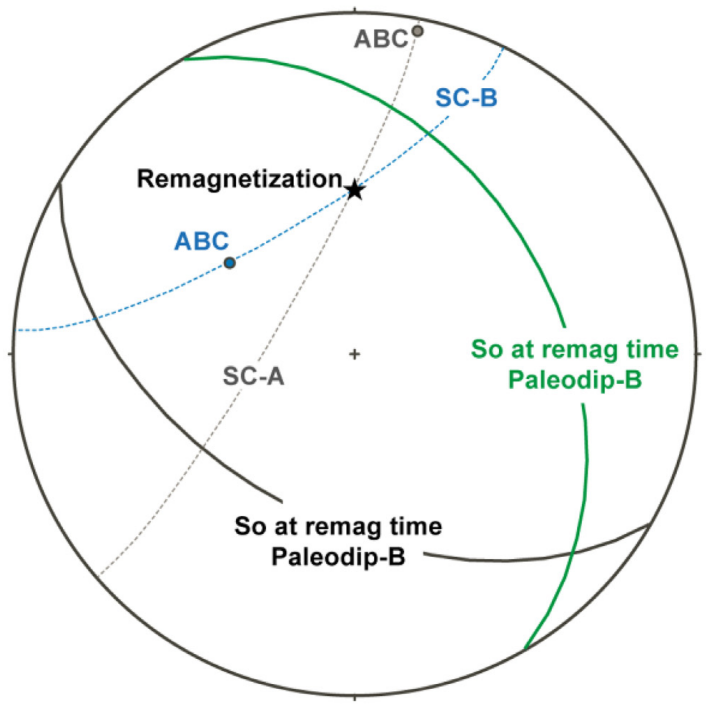

(c) B plane $\mathrm{CW}$ rotates from $0^{\circ}$ to $55^{\circ}$

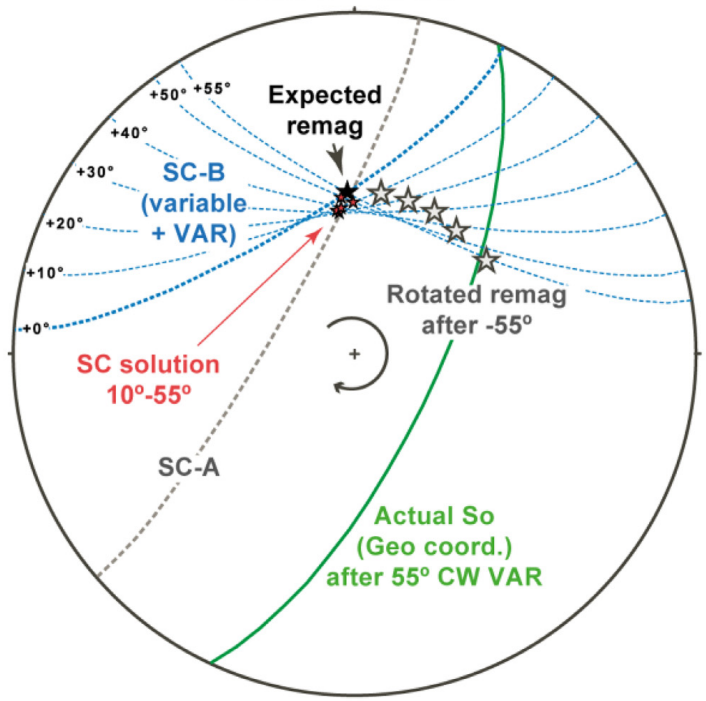

(b) Remagnetization is folded

(30 each LIMB)

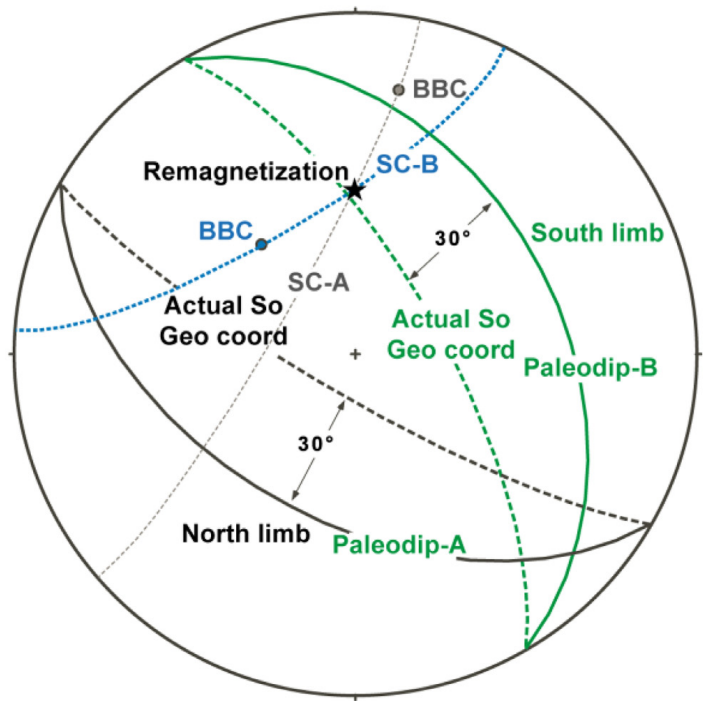

(d) B plane $\mathrm{CW}$ rotates from $0^{\circ}$ to $-55^{\circ}$

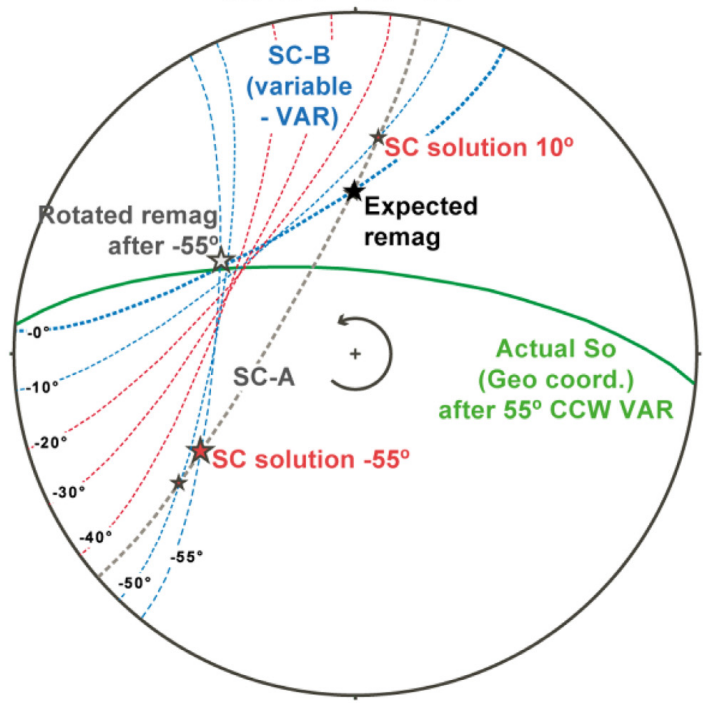

Figure 3. VAR and the SCI method. A synfolding magnetization (a) affecting a fold characterized by two limbs that is subsequently re-folded (b) and finally undergoes a (variable) VAR (c and d). In the first case (c) the bedding plane B rotates $\mathrm{CW}$ up to $55^{\circ}$ and in the second case (d) it rotates the same amounts in a CCW manner.

$\mathrm{SC}^{*}$. Error in declination and inclination is obtained comparing this expected result with pmag0 (which is equivalent to the crossing point between the small circles before the vertical axis rotation $\mathrm{SC} 1$ and SC2: DEC, INC).

These results allow us to plot the errors in declination and inclination versus obliquity in the first case and inclination in the second for different initial parameters (Fig. 7). The starting setting is: $\operatorname{dec}_{0}=0^{\circ}, \operatorname{inc}_{0}(\tau)=15^{\circ}$, non-coaxiality $(\Omega)=15^{\circ}$, obliquity $(\alpha)=15^{\circ}$, dip after folding $\left(\sigma=15^{\circ}\right)$ and $\operatorname{VAR}(\beta)$ variation from $50^{\circ} \mathrm{CCW}$ to $50^{\circ} \mathrm{CW}$. It is important to mention that not all the situations yield a solution because not all pairs of small circles intersect (this particular setting happens for $\mathrm{CCW}$ rotations).
In the first case (errors versus obliquity, Fig. 7a), we can observe, for $\mathrm{CW}$ rotation, how the declination error decreases when obliquity is close to $90^{\circ}$ while the inclination error, conversely, increases around this value. The effect of CCW rotation is the opposite; declination error increases when obliquity is close to $90^{\circ}$ becoming impossible to obtain a solution for high values of VAR. For a higher non-coaxiality and CW rotation, errors are slightly smaller. The same happens for a higher inclination.

In the second case (errors versus inclination, Fig. 7b), we can observe how declination error is constant, independently of the inclination value, although it is not proportional to the VAR. On the other side, inclination error exponentially decreases when inclina- 
(a)
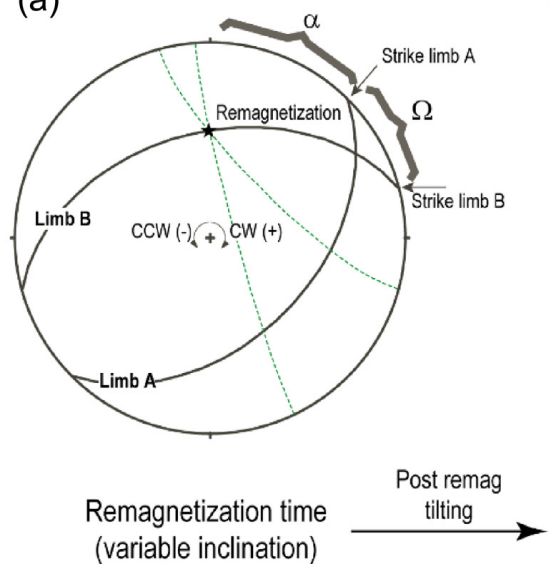

(b)

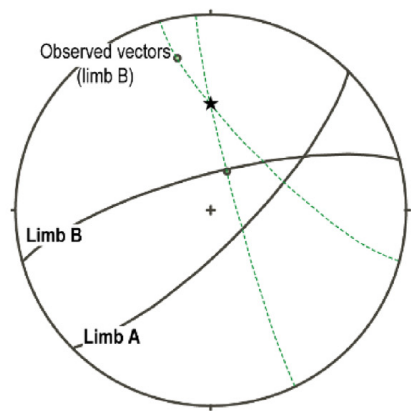

(c)

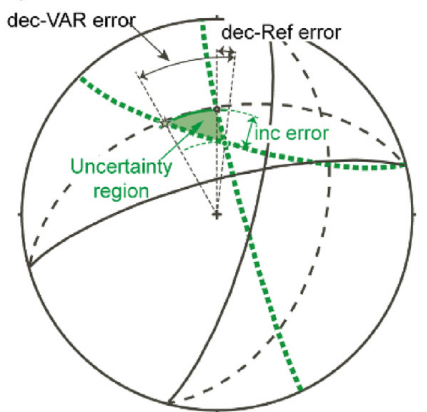

Geographic Reference System
(observed vectors and planes) $\stackrel{\text { VAR }}{\longrightarrow} \begin{gathered}\text { Dec \& Inc Errors } \\ \text { Limb A rotates }-30^{\circ}\end{gathered}$

Figure 4. Definition of variables controlling the uncertainty and errors related to the occurrence of VAR in the SC methods. $\Omega$ : primary non-coaxiality; $\alpha$ : obliquity between the strike and the remagnetization declination.

\section{CW VAR on limb W}

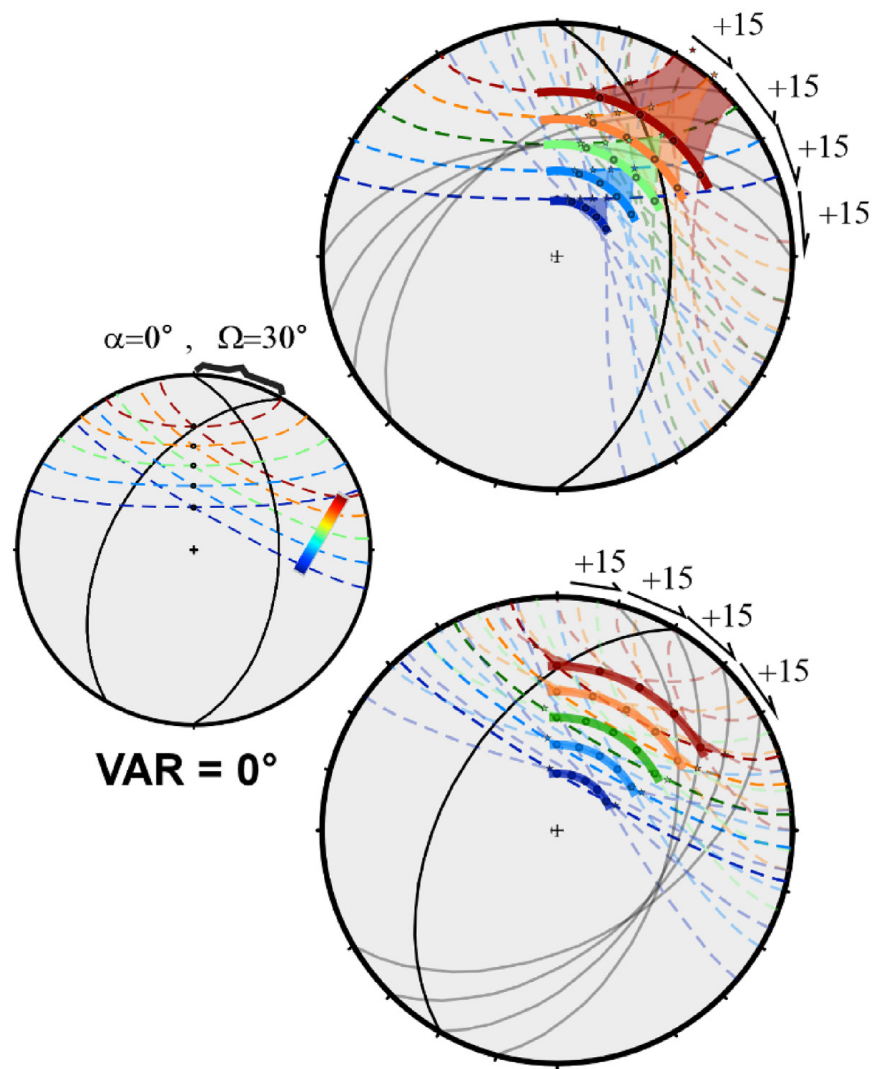

CW VAR on limb E

\section{CCW VAR on limb $\mathbf{W}$}
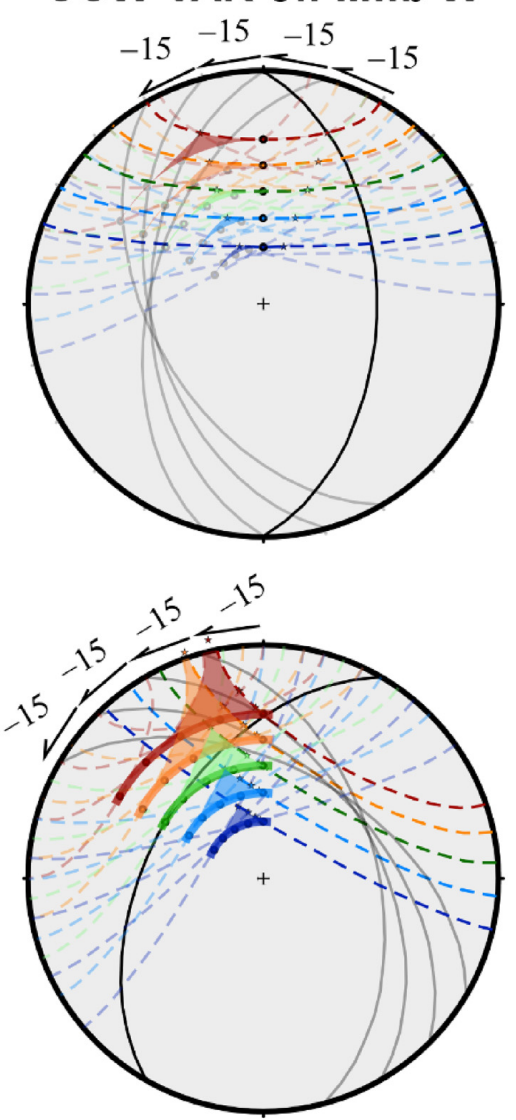

CCW VAR on limb E

Figure 5. Uncertainty and errors in the SCI method caused by variable inclinations $(\tau)$ and VAR. Different inclinations are indicated by a colour scale (cold colours, steep inclinations; warm colours, shallow inclinations). The smaller stereonet on the left indicates the results obtained for a standard case without VARs, with different inclinations of the reference direction (indicated by colour scale).

tion increases. Moreover, the SCI method tends to be valid (small circles cross) for higher VARs, with steeper inclinations.

In conclusion, this simplistic approach (just two sites of a twolimb fold) helps illustrating the important effect of VARs in palaeomagnetic estimation when the SCI method is applied. However, and due to the large number of variables involved and the importance of the initial setting, it is difficult to describe a simple pattern that governs the errors. The only simple observation is that shallow inclinations of the palaeomagnetic remanence will produce greater errors in its determination. 
$\alpha 45^{\circ}$

Constant $\Omega\left(30^{\circ}\right)$, variable $\tau\left(30^{\circ}, 45^{\circ}, 60^{\circ}\right)$

Variable VAR, OVAR $= \pm 30^{\circ} \pm 30^{\circ}$
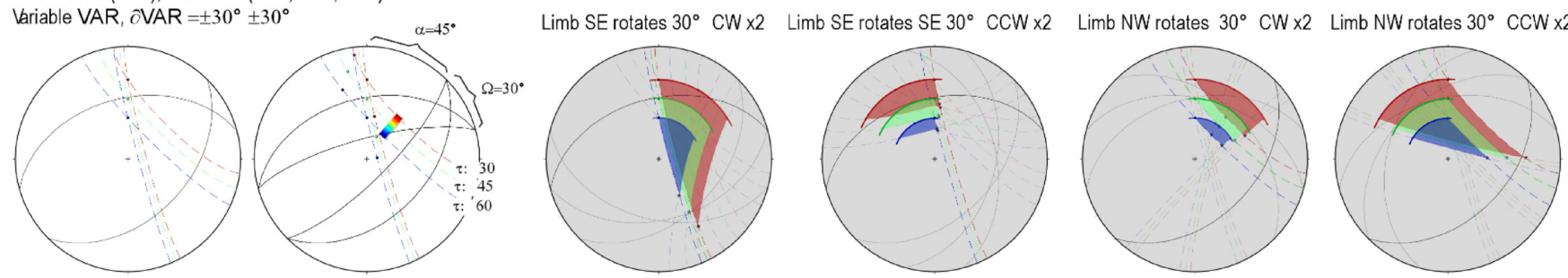

$\alpha 90^{\circ}$

Constant $\Omega\left(30^{\circ}\right)$, variable $\tau\left(30^{\circ}, 45^{\circ}, 60^{\circ}\right)$

Variable VAR, $\partial$ VAR $= \pm 30^{\circ} \pm 30^{\circ}$
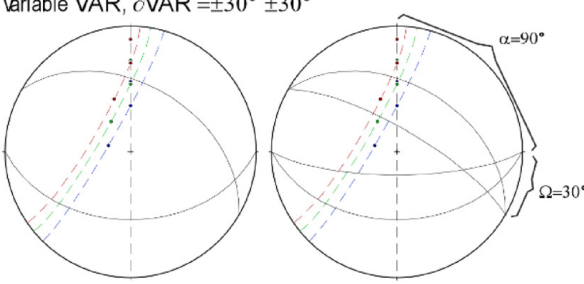

Limb S rotates $30^{\circ} \mathrm{CW} \times 2$
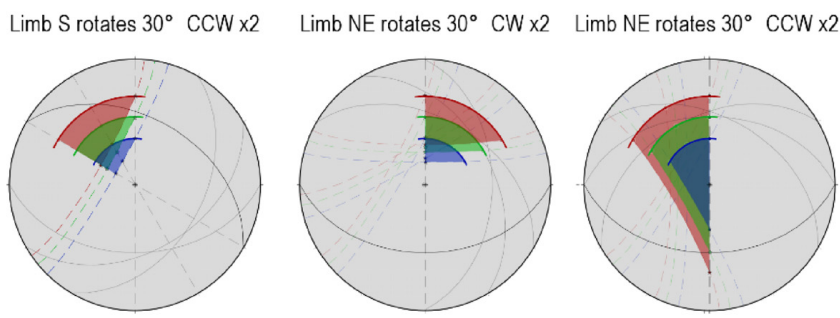

$\alpha 135^{\circ}$

Constant $\Omega\left(30^{\circ}\right)$, variable $\tau\left(30^{\circ}, 45^{\circ}, 60^{\circ}\right)$ Variable VAR, $\partial$ VAR $= \pm 30^{\circ} \pm 30^{\circ}$
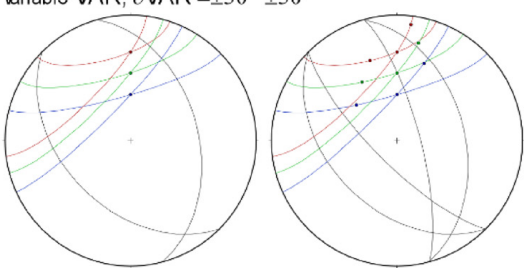

Limb SW rotates $30^{\circ} \mathrm{CW} \times 2$

Limb SW rotates $30^{\circ} \mathrm{CCW} \times 2$
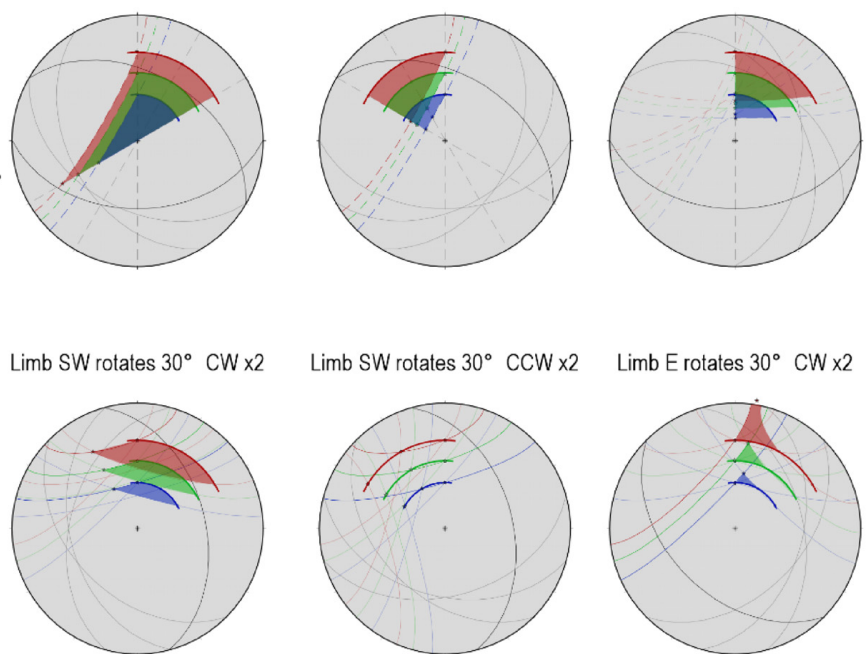

Figure 6. Uncertainty regions and errors in the SCI method caused by variable obliquities $(\alpha)$, VAR and inclinations $(\tau)$. Left-hand column: represents the remagnetization time acquisition. Central column exemplifies the orientation of the remagnetization vectors and planes after the following coaxial deformation. The right-hand columns illustrates the effect of the VAR undergone in one flank in the SCI result (VAR displays a different magnitude and sense in each row).

\section{SIMULATING A POPULATION OF n BEDDING PLANES}

After the evaluation of two-planes models, in this section we show simulations of a population of $n$ planes. We only show a few examples of the models in order to observe how different factors can affect to the SC solution. The reader is encouraged to read the Supplementary Materials 4 and 5, where the entire set of VAR and dHARs models, respectively, are available. The simulations can be considered realistic and comparable to real case-studies and therefore help to constraint the real impact of VARs and dHARs in the SC methods through the error in the calculation of the remagnetization direction and in the palaeodips for each site (Figs 8 and 9).

\subsection{VAR models}

\subsubsection{Starting VAR models}

The initial setting of VAR models (Fig. 8a) is a pre-remagnetization symmetric fold that acquires a remagnetization $\left(D=000^{\circ} ; I=\right.$ $\left.15^{\circ}, 45^{\circ}, 75^{\circ}\right)$. The models consider 30 sites, 15 in each limb, with $45^{\circ}$ dip and an original random dispersion in strike of $\pm 10^{\circ}$ (i.e. $\Omega=20^{\circ}$ ) from the main structural trend. The trend of the fold and therefore the strikes of sites are variable in the models according to $\alpha\left(0^{\circ}, 45^{\circ}\right.$ and $90^{\circ}$ values for $\left.\alpha\right)$.

Starting from the initial setting (Fig. 8a) differential VARs were applied (Fig. 8b) to 10 sites of each limb (then, five sites of each limb are not affected by VAR). These VARs are applied randomly in each site within a range of $30^{\circ}$ : from $-30^{\circ}$ to $0^{\circ}$ for $\mathrm{CCW}$ rotation models, from $-15^{\circ}$ to $+15^{\circ}$ for symmetric model and from $0^{\circ}$ to $+30^{\circ}$ for $\mathrm{CW}$ rotation model. Rotated bedding and palaeomagnetic directions are used as input data for models. In one set of the models the remagnetization direction and the palaeodips are calculated and compared with the original remagnetization direction $\left(D=000^{\circ} ; I\right.$ $\left.=15^{\circ}, 45^{\circ}, 75^{\circ}\right)$ as well as with the original palaeodips $\left(45^{\circ}\right.$, Fig. $\left.8 \mathrm{~b}\right)$. In the other set of models, palaeodips are calculated forcing to the original remagnetization direction (Fig. 8c). A dispersion parameter $\mathrm{k}$ (Fisher 1953) of 10000 and 50 bootstraps have been considered in the SCI calculations, which have been done using Python code based in the pySCu software (Calvín et al. 2017a).

\subsubsection{Errors in the calculated remagnetization direction}

In an overall view, the error in the calculated remagnetization direction strongly depends on $\alpha$ and on the original inclination in the remagnetization direction (Fig. 8b). In general, we obtain higher errors for lower inclinations especially for high $\alpha$ values (i.e. 45 and $90^{\circ}$ ) and, as a general rule, the calculated direction always presents higher inclinations than the original one. For $\alpha=0^{\circ}$ models, error is mostly in declination but not in inclination.

\subsubsection{Errors in the palaeodips}

Errors in the calculated palaeodips are significant in VARs models. While they are quantitatively similar, they show different pat- 
(a) Errors vs. Obliquity
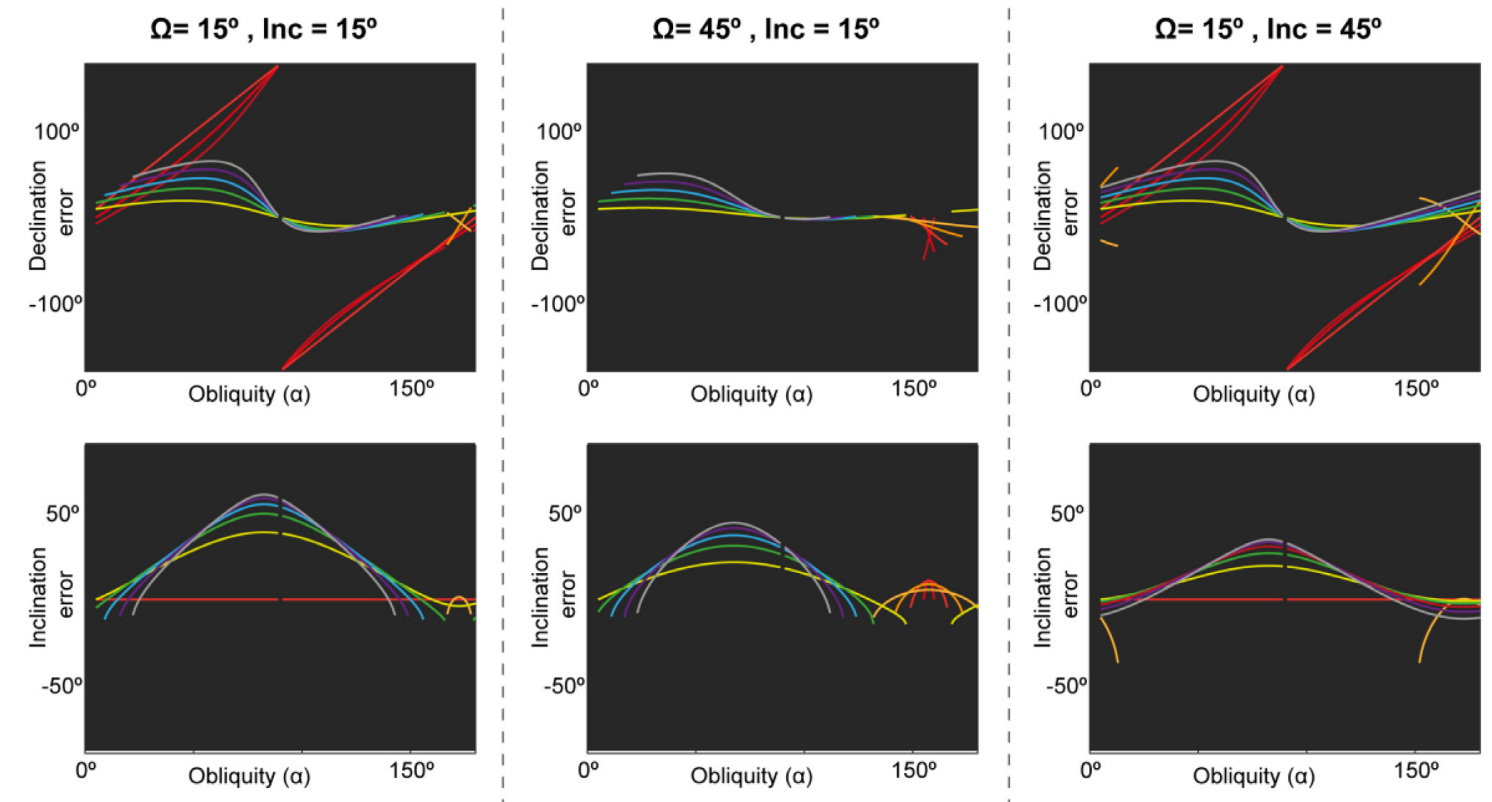

(b) Errors vs. Inclination
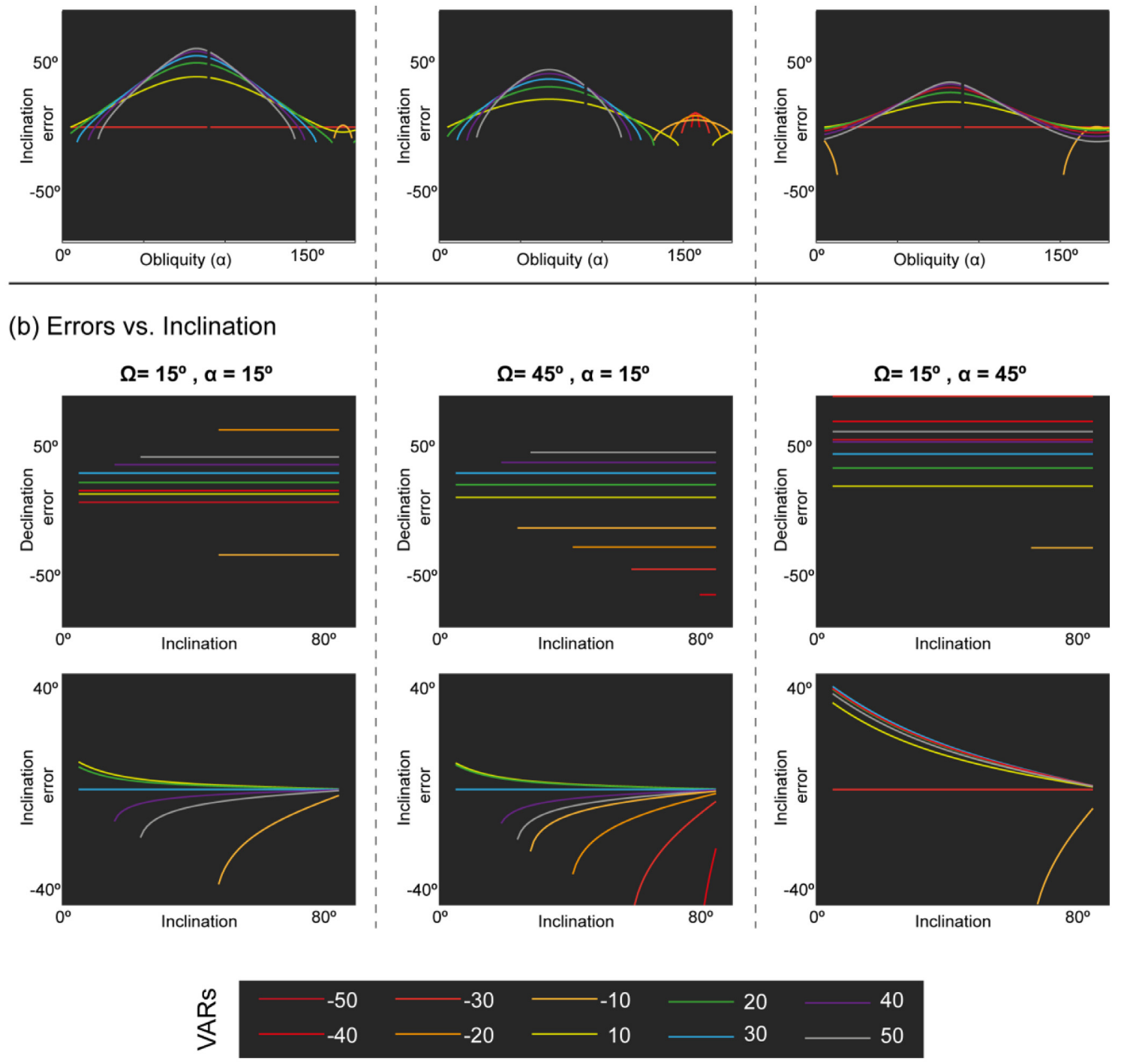

Figure 7. Mathematical modelling of errors for two limbs. Declination and inclination errors versus obliquity (a) and inclination of the remagnetization direction. Models consider different values of non-coaxiality $(\Omega)$, inclination and/or obliquity. VAR varies from $-50^{\circ}$ in $10^{\circ}$ steps to $+50^{\circ}$.

terns depending on the configuration of the model. For example, symmetric models (Fig. 8b) show equal errors in all sites of each limb independently of the recorded VAR, the palaeodip is overestimated in one limb and underestimated in the other. On the other hand, in $\mathrm{CCW}$ and $\mathrm{CW}$ models the palaeodip error varies symmetrically in each limb depending on the recorded VAR. And the same happened in $\mathrm{CW}$ and $\mathrm{CCW}$ models in which the remagnetization direction is forced to the expected one (Fig. 8c), but in this case the sites with no VAR are those who have no error, whereas in the previous one the sites with no error are those with intermediate VAR (further in the Supplementary Material 4). 
(a)

$$
\operatorname{Inc}=15^{\circ}, \alpha=90^{\circ}
$$

Inc $=45^{\circ}, \alpha=45^{\circ}$
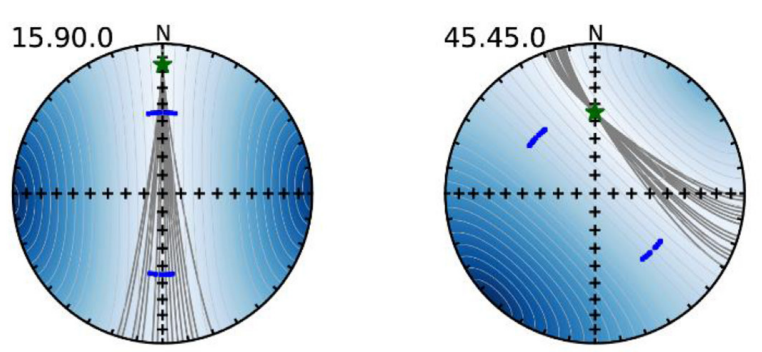

$\operatorname{Inc}=75^{\circ}, \alpha=0^{\circ}$

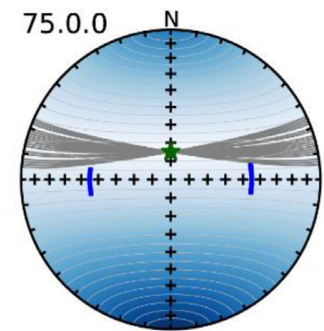

(b)
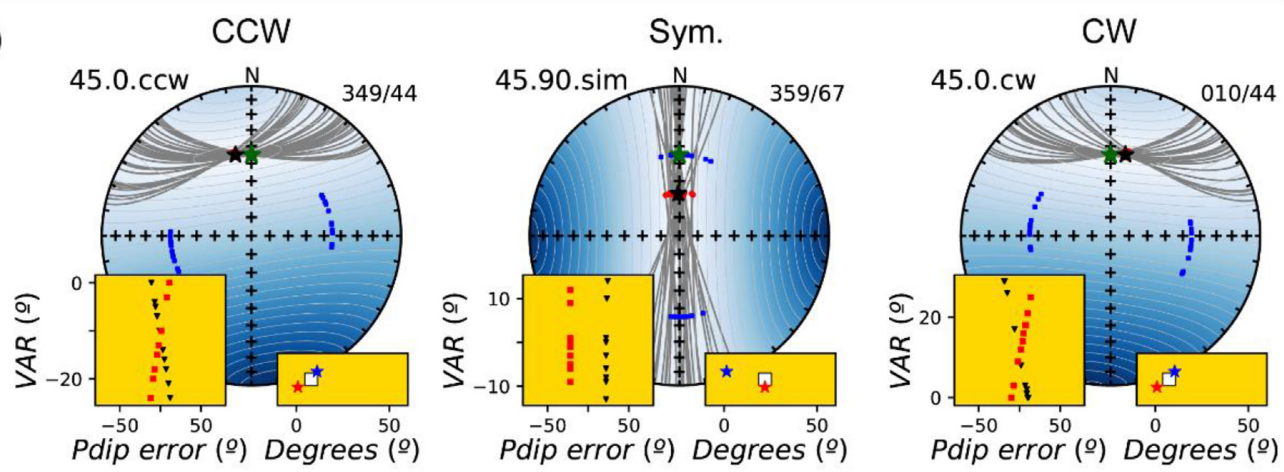

(c)
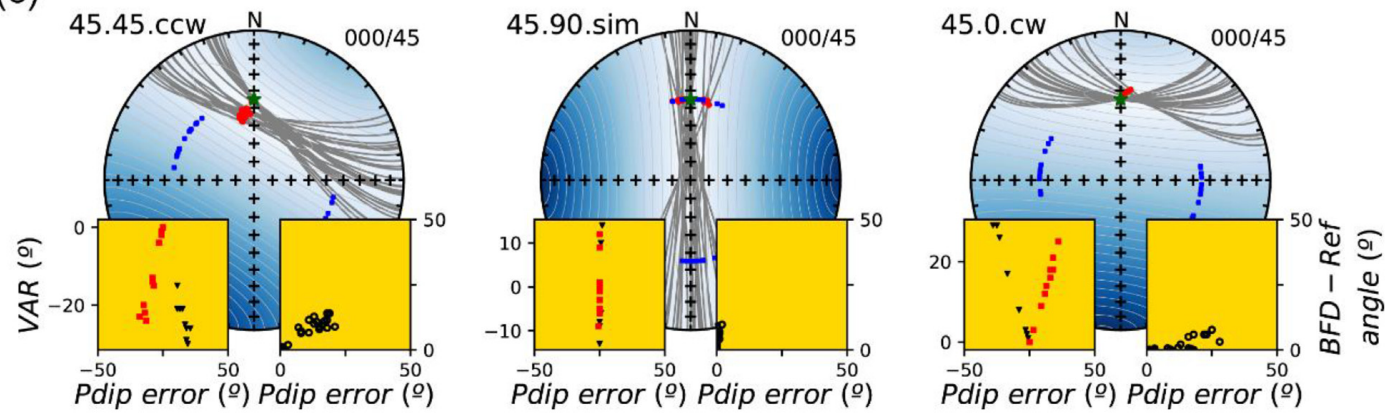

Figure 8. (a) Original configuration of some synthetic models before applying VARs. (b) Errors in the calculated remagnetization direction and palaeodips for some examples of VAR models. (c) Palaeodip errors derived from VAR models carried out with the original remagnetization direction. The entire set of models are in supplementary material 2.1 and 2.2. The name of each model (upper-left sector) is a dot-delimited code showing the inclination of the remagnetization direction, the obliquity $(\alpha)$ and the recorded VAR. Green and black stars: original and calculated remagnetization directions respectively; blue dots: bedding poles; red dots: best fit directions (i.e. the closest direction over each SC to the calculated reference). Low-left inset in (b) and (c): each colour represent sites from each limb. Low-right inset in (b): white square, blue star and red star, overall error, declination and inclination error of the calculated remagnetization direction. Low-right inset in (c): palaeodip errors plotted versus the angle between the best fit direction and the reference. Bluish contour plot: A/n values (see Calvín et al. 2017a), in which light colours represent lower values.

\subsection{Evaluating dHAR models}

\subsubsection{Starting dHAR models}

The starting point for dHAR models (Fig. 9a) are folded sites affected by a remagnetization $\left(D=000^{\circ} ; I=15^{\circ}, 45^{\circ}, 75^{\circ}\right)$, with a random dip (between $-45^{\circ}$ and $+45^{\circ}$ ) and an original random dispersion in strike of $\pm 10^{\circ}$ from the main structural trend (i.e. $\Omega=20^{\circ}$ ). As in the VAR models, different $\alpha$ values are considered. Then, each site is tilted a random value between $-45^{\circ}$ and $45^{\circ}$ according to a horizontal rotation axis defined by the parameter $\gamma$ (angle between the original strike of each site and the non-coaxial post-remagnetization rotation axis). Note that post-remagnetization tilting can increase or decrease their preremagnetization dip up to a maximum of $\pm 90^{\circ}$ (positive or negative dips refer to opposite limbs considering the same strike and the right hand rule). Post-remagnetization rotated data are used as input data, as in VAR models, for calculating the remagnetization direction and the palaeodips (Fig. 9b), also fixing the remagnetization direction to the known direction in one of the set of models (Fig. 9c).

\subsubsection{Errors in the calculated remagnetization direction and the palaeodips}

One of the main features of dHARs models, and a difference from VARs models, is that the non-coaxiality changes the trend of the SCs but also their apical angles. This leads to similar errors independently of the non-coaxiality angle $\left(\gamma=45^{\circ}\right.$ or $90^{\circ}$, Fig. 9b).

As expected, coaxial models $\left(\gamma=0^{\circ}\right)$ do not present errors in the remagnetization direction nor in palaeodip, either. In regard to non-coaxial models $\left(\gamma=45^{\circ}\right.$ and $\left.90^{\circ}\right)$, they also present low errors in the calculated remagnetization direction (less than 10-15 in most cases), with larger errors in declination for high inclination 
(a) Starting models

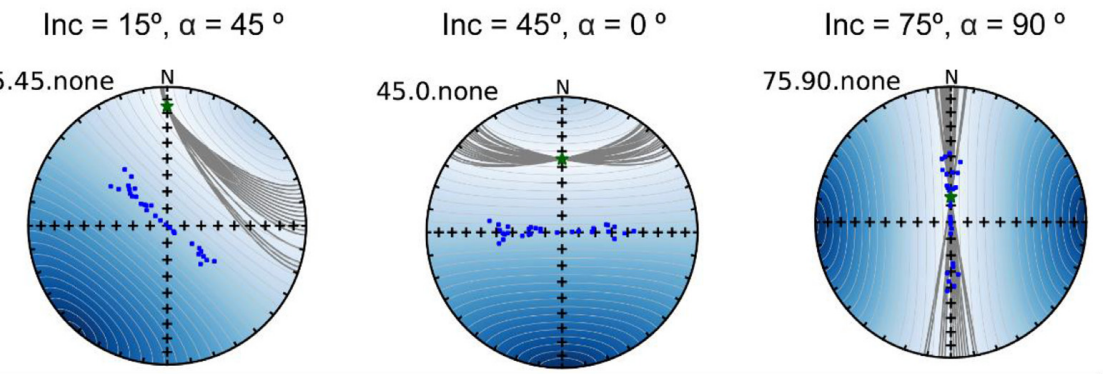

(b) Errors in the remagnetization direction and the paleodips
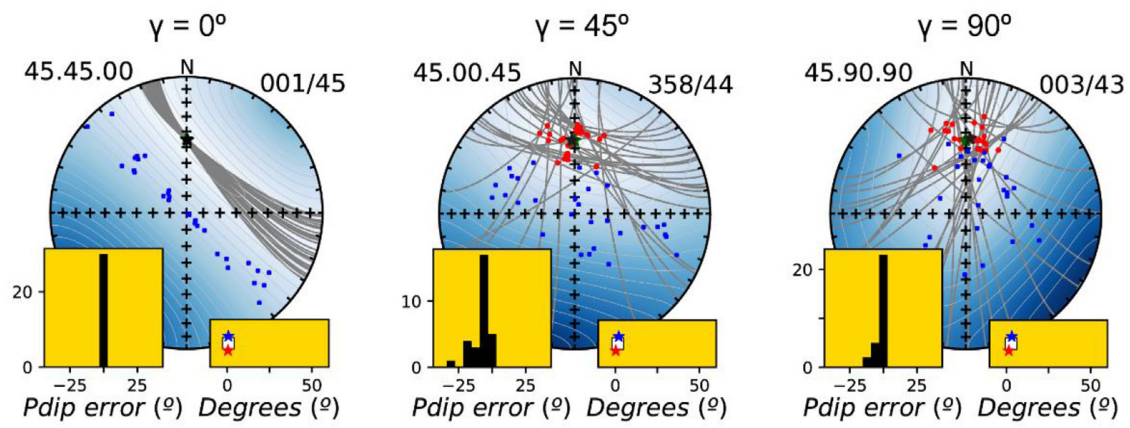

(c) Errors in the paleodip considering a fixed reference
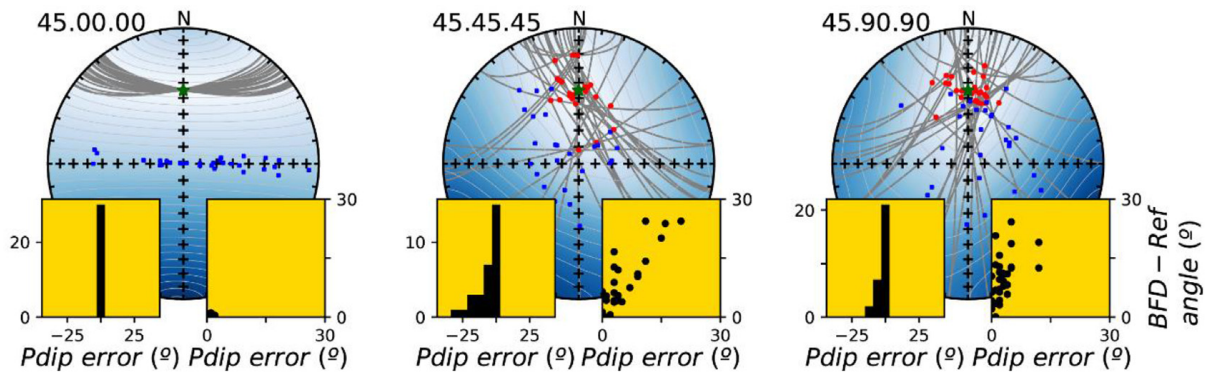

Figure 9. (a) Original configuration of some synthetic models before applying dHARs. (b) Errors in the calculated remagnetization direction and palaeodips for some examples of dHAR models considering different non-coaxiality $(\gamma)$. (c) Palaeodip errors derived from dHAR models carried out with the original remagnetization direction. The entire set of models are in supplementary material 2.3 and 2.4. . The name of each model (upper-left sector) is a dot-delimited code showing the inclination of the remagnetization direction, the obliquity $(\alpha)$ and $\gamma$. Green and black stars: original and calculated remagnetization directions, respectively; blue dots: bedding poles; red dots: best fit directions (i.e. the closest direction over each SC to the calculated reference). Low-left inset in (b) and (c): each colour represent sites from each limb. Low-right inset in (b): white square, blue star and red star, overall error, declination and inclination error of the calculated remagnetization direction. Low-right inset in (c): palaeodip errors plotted versus the angle between the best fit direction and the reference. Bluish contour plot: A/n values (see Calvín et al. 2017a), in which light colours represent lower values.

values of the original remagnetization. On the other hand, palaeodip errors are between $0^{\circ}$ and $25^{\circ}$ in all cases, with a dominance of sites with neglectable errors, both in models in which the reference was calculated (Fig. 9b) or fixed to the expected direction (Fig. 9c). Further explanations are given in the Supplementary Material 5.

\section{DISCUSSION}

\subsection{Approximations trying to add VAR}

As it is shown in the presented models, VARs may have a strong influence (systematically larger than dHARs) in both the determination of the remagnetization direction (the SCI solution) and the subsequent palaeodip analysis when using the SC tools. In this section, we evaluate the error generated in the previous synthetic models using three different approaches.

(1) In our previous models (as well as in most published works using the SCs method), the errors associated with the palaeodip were not considered. However, and following the work by Calvín et al. (2017a), we can evaluate this uncertainty through bootstrap statistics. Although this is not related to VARs, the method grants greater flexibility that could eventually minimize the effect of small VARs. However, as Fig. 10b shows, the solution is similar to the one obtained without considering the error in the attitude of bedding (Fig. 8).

(2) Theoretically, starting from the hypothesis of an instantaneous remagnetization and not considering here spurious results, solutions must converge for bed restoration, applying horizontal rotations (described by the small circles whose axis is the strike 
(a) Original data
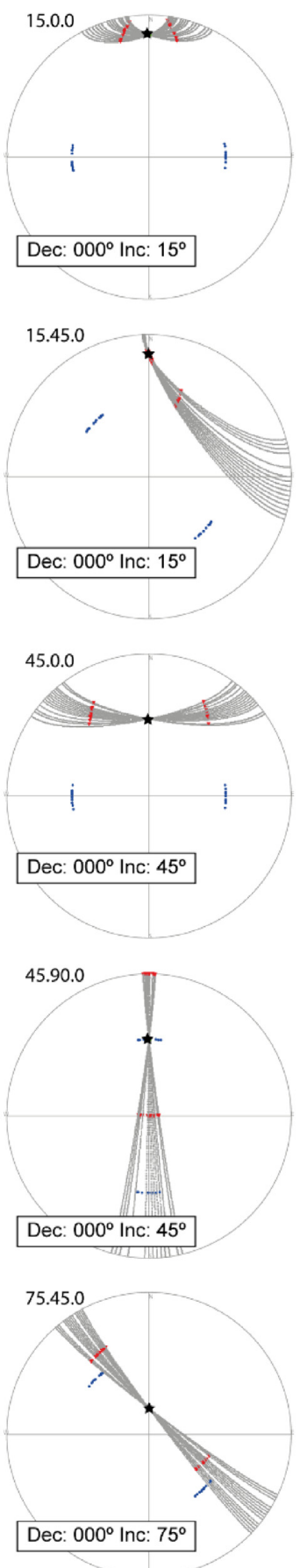

(b) Affected by VAR
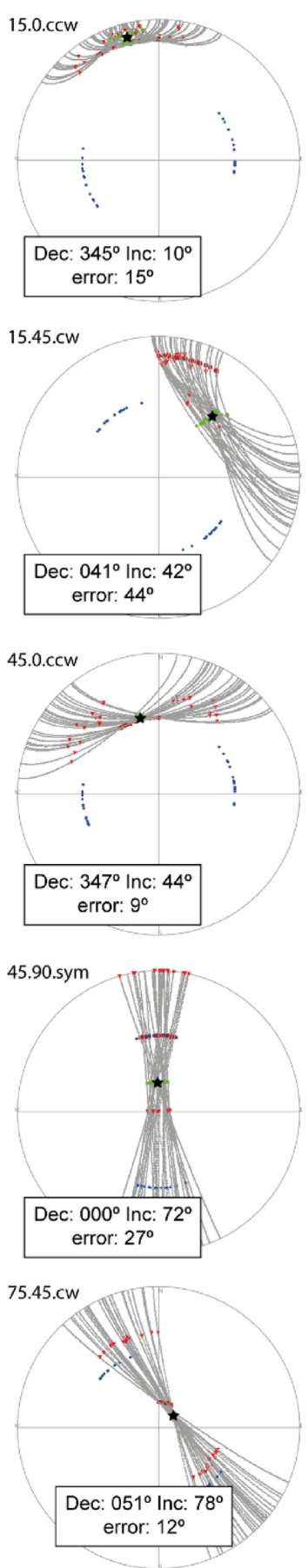

(c) Correcting VAR
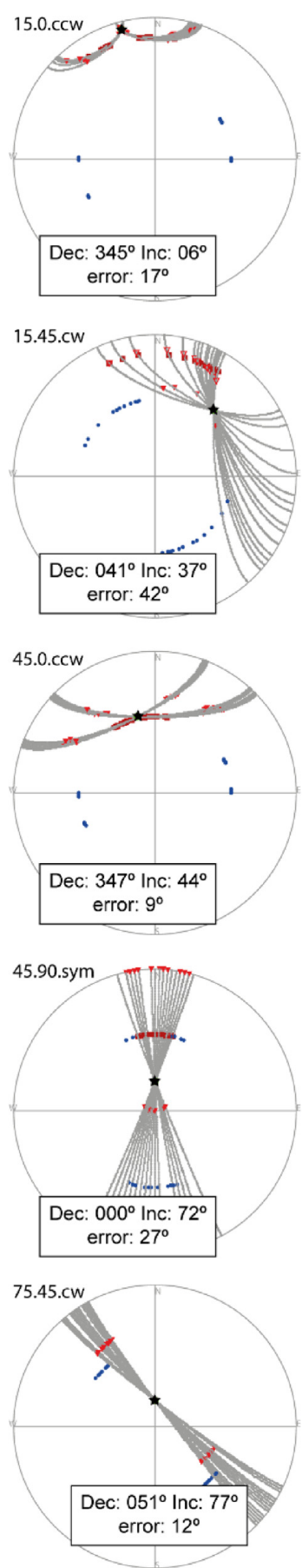

(d) Considering random VAR
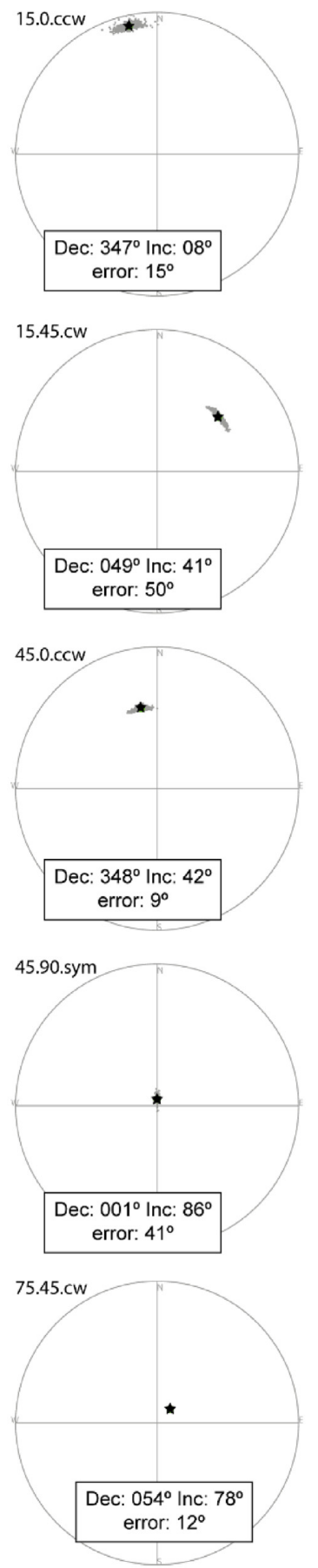

Figure 10. SCI solution (black star) in different scenarios. Synthetic models showing (a) original data without VAR, (b) the same after being affected by VAR (CW, CCW or symmetric), equivalent to previous figures, (c) forcing all SC to pass through the SCI solution and (d) after 500 random simulations adding a different VAR for each site. The inset shows the calculated SCI solution and the error from the original remagnetization direction. See Appendix C.

of beds) and vertical axes rotations in the sense contrary to those underwent by beds during their tectonic folding. In principle, both types of rotations are commutative and no ambiguity should be derived from the order in applying restorations. Having said that, we can assume that variability in SCs is only caused by vertical axis rotations. In this case, we can force small circles to rotate in order to converge in the reference direction or simply to approach it with a minimum angular displacement. This has been done modifying the "Virtual Palaeomagnetic Directions (VPD)" software (Ramón et al. 2017). Neither in this case we improve the results (Fig. 10c), and we observe similar errors in the calculated direction than those obtained in previous approaches. Despite this non-effectiveness of the approach, the modification of the VPD software can still be useful to detect individual sites likely affected by VARs or dHARs.

(3) Finally, we have added a second option to the VPD software: starting off an initial set without VAR to simulate the effects of a 
random vertical axial rotation for each site. The first conception was based on rotating each small circle according to a gradual VAR to calculate a SCI solution for all possible combinations of small circles. For example, having 10 sites with a gradual VAR from $50^{\circ} \mathrm{CCW}$ to $50^{\circ} \mathrm{CW}$ every $5^{\circ}$ for each one, there would be $50^{10}=9 * 10^{16}$ solutions. Given the huge number of calculations, we decided to change the approximation to another one based on the bootstrapping concept. We simulate 500 hypothetical cases in which we add a random VAR with a maximum value for each site. A SCI solution is obtained for each case and finally all together are averaged. After this procedure, errors are similar or larger than in the previous approaches (Fig. 10).

\subsection{Hints to discover VARs and dHARs in the SC methods}

Errors derived from SC tools can be significant if some of the starting hypotheses are not fulfilled, as for example the occurrence of post-remagnetization VARs or dHARs. Sometimes it can be difficult to determine the presence of these processes leading to errors in the calculation of remagnetization directions or in structural reconstructions. As it is inferred from section 5.1, automatic solutions can be dangerous and even lead us to larger mistakes. Independent geological data can provide indications of the existence of VARs or dHARs. Furthermore, synthetic models give us clues to suspect that something is wrong if we detect similar patterns in real cases.

\subsubsection{Detecting VARs}

VARs, even moderate as the simulated in our models (from $0^{\circ}$ to $30^{\circ}$ ), generate significant errors in the calculated remagnetization and in the palaeodips, but, fortunately, these errors display characteristic stereographic patterns. It must be stressed that only VARs taking place after the remagnetization acquisition can be detected.

(1) In VAR models, the calculated remagnetization tends to show higher inclinations, within the limits of the apical angle (Ap) of the SCs, and hence tends to be placed in the central sectors of the SCs. Therefore, calculated directions with inclinations lower than the limit imposed by the SCs are likely actual directions and, on the contrary, inclinations limited by Ap are suspicious of being affected by VARs. Comparison of the inclination with external data (e.g., the apparent polar wander path) can be decisive in identifying VARs.

(2) In gradual and moderate VARs, as in the analysed models, the SC distribution does not give any clue about the presence of VARs. However, local VAR in a small subset could be identifiable.

(3) The analysis of the palaeodips can be very useful to detect VARs, and we must encourage to perform this analysis considering the $\alpha$ parameter. Systematic higher dips on limbs dipping in one sense versus the opposite limbs (for $\alpha=0^{\circ}$ ) or non-sense reconstructed structures (for $\alpha=90^{\circ}$ ) can be indicators of the occurrence of VARs.

\subsubsection{Detecting dHARs}

Analysed models show that non-coaxiality is difficult to detect only from errors in the calculated remagnetization and in the paleodips. Fortunately, our simulations demonstrate that errors derived from non-coaxiality are low and generally assumable in structural reconstructions. Likely, the only way to detect non-coaxiality is by analysing the SC distribution as well as the bedding distribution.
Bedding poles showing a higher scattering in the cylindrical best fit, according to the general structural trend, are suspicious of being the result of non-coaxiality.

\subsubsection{Key points to detect VARs or dHARs}

Although not so different from the routines usually followed by the palaeomagnetic community, here we want to propose a simple workflow to help detecting the presence of VARs or dHARs in our palaeomagnetic data set. We must take into account that, as we can see from the synthetic models, univocal clues do not exist because the large amount of variables involved generates particular configurations in every case (inclination of the remagnetization, obliquity, sense of VARs, etc.) and thus, promotes different results.

(1) First of all, the apparent syn-folding character caused by internal deformation, overlapping or improper restoration of palaeomagnetic vectors (Pueyo et al. 2016) must be ruled out.

(2) Once the synfolding character is reliable, one should check whether there are any evidences in the scientific literature of the presence of VARs or dHARs in the study area. These evidences may come either from structural or other palaeomagnetic studies supported in primary magnetizations.

(3) One should consider what the expected palaeomagnetic direction might be. If we have some hints, for example of the expected inclination, they could give us clues about the possible influence of VARs or dHARs in our data. For example, the regional Kiaman remagnetizations that affect the Variscan - Alleghanian orogen show low inclinations (Van der Voo \& Torsvik 2012, and references therein) due to their equatorial location during the Late Palaeozoic; then, particular attention should be given to these cases with high potential of errors due to VARs. On the other hand, perhaps it is difficult to know the expected direction, but it is easier to define the Global Apparent Polar Wander Path for the study area. In some fortunate areas, as North West Africa for the Mesozoic, the expected directions change in declination but with almost no change in inclination. On the other hand, previous models indicate that the presence of VARs lead to higher inclinations than the actual ones. Therefore, anomalous higher inclinations than the expected in the African example indicate the presence of VARs.

(4) In a scenario affected by dHARs, it is expected that not every site records the same amount of deformation during the different deformational events, that is there will be some sites more affected by the pre- or post-remagnetization deformational stages, and others affected by both. Then, it is possible to separate sites affected mainly by the pre-remagnetization deformation from those mainly affected by the post-remagnetization one. After that, the separate folding analyses (calculation of the axis, axial plane, etc.) of both populations can give clues about the degree of coaxiality between both deformational stages (see Torres-López et al. 2018).

(5) The oroclinal test (Pastor-Galán et al. 2017, and references therein) can give an idea about post-remagnetization VARs. However, this test must not be used with results derived from SC tools, especially when the remagnetization direction is also obtained with this method. Comparing the Symmetric models of Fig. 8, we can observe that the variations in declination do not correspond with variations in strike when the remagnetization direction is previously unknown (Fig. 8b), but correlates when the remagnetization direction is determined from different sources (Fig. 8c).

(6) Finally, we would like to emphasize again from the results derived from the synthetic models: (i) anomalies in the restoration of the structure can give direct clues of the presence of VARs and 
(ii) the presence of dHARs give small errors, and this process can be evaluated by a random distribution of the small circles.

\section{CONCLUSIONS}

Small Circle tools constitute a set of workflows to evaluate interfolding remagnetizations (i.e. those acquired between two separated deformational periods). Using these tools, it is possible to calculate the original remagnetization direction as well as the attitude of bedding at the remagnetization acquisition time (i.e. those that are a consequence of the first deformational stage). However, these tools are based on some starting hypotheses; one of them is the coaxiality between the pre- and post-remagnetization deformation. In this paper, we evaluate the errors in the calculated remagnetization direction and in the palaeodips when this hypothesis is not fulfilled. In particular, we evaluate both the presence of post-remagnetization vertical axis rotations (VARs) and the action/motion of two different horizontal axes rotations (dHARs). For that, we first test simple models with two plane sets that allow to, isolate the variables and to quantify the errors in the calculated remagnetization direction under different scenarios (i.e. considering different inclinations of the remagnetization direction, different obliquity between the main structural trend and the declination of the remagnetization direction and different VARs). After that, the equations that govern the case of two limbs are calculated in order to quantitatively evaluate the same errors. The main conclusion derived from this approach is that it is difficult to define a simple pattern that governs the errors, except that the errors increase for lower inclinations of the remagnetization direction and for higher VAR values.

Furthermore, several synthetic models were done considering 30 bedding planes affected by differential VARs and dHARs considering different scenarios: different inclinations of the remagnetization direction, different declination and structural trend relationships and different degrees of non-coaxiality. Using these models, it is possible to calculate the error both in the remagnetization direction and in the palaeodips. Under VAR scenarios, the obtained errors are important, increasing the error in the remagnetization direction for larger angles between the declination and the main structural trend and for shallower inclinations. Errors in palaeodips show characteristic, symmetric patterns in the different limbs that can help to decipher the presence of VARs. On the other hand, the presence of dHARs has a minor effect both in the calculation of the remagnetization direction and in the palaeodips, but they are difficult to detect because errors do not show particular patterns.

Therefore, the presence of non-coaxiality can hinder the correct use of the SC tools, but non-coaxiality (especially VARs) can be detected after a careful analysis of the pattern of the small circles and also considering the regional geology.

\section{ACKNOWLEDGEMENTS}

The authors acknowledge the constructive revisions and comments from Richard Elmore and Martin Chadima, as well as from the editor Eduard Petrovsky. Research financed by the projects DR3AM- CGL2014-55118 and CGL2016-77560-C2 from the Spanish Ministry of Science (MINECO) and by the Applied Geology (GeoAP-E0117R) and Geotransfer groups of the Government of Aragon, as well as by the project BU235P18 (Junta de Castilla y Leon, Spain) and the European Regional Development Fund (ERD). It has also benefited from the MAGIBER-II network
(CGL2017-90632-REDT) funded by the Ministry of Science, Innovation and Universities. Stereoplots were done with the software Stereonet (Allmendinger et al. 2012; Cardozo \& Allmendinger 2013).

\section{REFERENCES}

Allerton, S., 1994. Vertical-axis rotation associated with folding and thrusting: an example from the eastern Subbetic zone of southern Spain, Geology, 22, 1039-1042.

Allerton, S., 1998. Geometry and kinematics of vertical-axis rotations in fold and thrust belts, Tectonophysics, 299, 15-30.

Allmendinger, R.W., Cardozo, N. \& Fisher, D.M., 2012. Structural Geology Algorithms, Cambridge Univ. Press.

Antolín, B., Schill, E., Grujic, D., Baule, S., Quidelleur, X., Appel, E. \& Waldhör, M., 2012. E-W extension and block rotation of the southeastern Tibet: unravelling late deformation stages in the eastern Himalayas (NW Bhutan) by means of pyrrhotite remanences, J. Struct. Geol., 42, 19-33.

Baidder, L., Michard, A., Soulaimani, A., Fekkak, A., Eddebbi, A., Rjimati, E.-C.C. \& Raddi, Y., 2016. Fold interference pattern in thick-skinned tectonics; a case study from the external Variscan belt of Eastern AntiAtlas, Morocco, J. Afr. Earth Sci., 119, 204-225.

Borradaile, G.J., 1997. Deformation and paleomagnetism, Surv. Geophys., 18, 405-436.

Calvín, P., Casas-Sainz, A.M., Villalaín, J.J. \& Moussaid, B., 2017b. Diachronous folding and cleavage in an intraplate setting (Central High Atlas, Morocco) determined through the study of remagnetizations, $J$. Struct. Geol., 97, 144-160.

Calvín, P., Villalaín, J.J., Casas-Sainz, A.M., Tauxe, L. \& Torres-López, S., 2017a. pySCu: A new python code for analyzing remagnetizations directions by means of small circle utilities, Comput. Geosci., 109, 3242.

Cardozo, N. \& Allmendinger, R.W., 2013. Spherical projections with OSXStereonet, Comput. Geosci., 51, 193-205.

Casas, A.M., Villalaín, J.J., Soto, R., Gil-Imaz, A., del Río, P. \& Fernández, G., 2009. Multidisciplinary approach to an extensional syncline model for the Mesozoic Cameros Basin (N Spain), Tectonophysics, 470, 3-20.

Deng, H., Koyi, H.A. \& Nilfouroushan, F., 2016. Superimposed folding and thrusting by two phases of mutually orthogonal or oblique shortening in analogue models, J. Struct. Geol., 83, 28-45.

Elmore, R.D., Muxworthy, A.R. \& Aldana, M., 2012. Remagnetization and chemical alteration of sedimentary rocks, Geol. Soc., Lond., Spec. Publ., 371, 1-21.

Enkin, R.J., Osadetz, K.G., Baker, J. \& Kisilevsky, D., 2000. Orogenic remagnetizations in the front ranges and inner foothills of the southern Canadian Cordillera: chemical harbinger and thermal handmaiden of Cordilleran deformation, Bull. geol. Soc. Am., 112, 929-942.

García-Lasanta, C., Casas-Sainz, A., Villalaín, J.J., Oliva-Urcia, B., Mochales, T. \& Speranza, F., 2017. Remagnetizations used to unravel large-scale fold kinematics: a case study in the Cameros basin (N Spain), Tectonics, 36(4), 714-729.

Henry, B., Rouvier, H. \& Le Goff, M., 2004. Using syntectonic remagnetizations for fold geometry and vertical axis rotation: the example of the Cévennes border (France), Geophys. J. Int., 157, 1061-1070.

Henry, B., Rouvier, H., le Goff, M., Leach, D., Macquar, J.-C., Thibieroz, J. \& Lewchuk, M.T., 2001. Palaeomagnetic dating of widespread remagnetization on the southeastern border of the French Massif Central and implications for fluid flow and Mississippi Valley-type mineralization, Geophys. J. Int., 145, 368-380.

Lewchuk, M.T., Evans, M. \& Elmore, R.D., 2003. Synfolding remagnetization and deformation: results from Palaeozoic sedimentary rocks in West Virginia, Geophys. J. Int., 152, 266-279.

López, M.A., Oliván, C., Oliva, B., Pueyo, E.L. \& Group, G., 2008. Pyrenean paleomagnetic databases, Geotemas, 10, 1219-1222.

MacDonald, W.D., 1980. Net tectonic rotation, apparent tectonic rotation, and the structural tilt correction in paleomagnetic studies, J. geophys. Res., 85, 3659-3669. 
McCaig, A.M. \& McClelland, E., 1992. Palaeomagnetic techniques applied to thrust belts, in Thrust Tectonics, pp. 209-216, ed. McClay, K.R., Springer Netherlands, doi:10.1007/978-94-011-3066-0_19.

McClelland-Brown, E., 1983. Palaeomagnetic studies of fold development and propagation in the Pembrokeshire old red Sandstone, Tectonophysics, 98, 131-149.

Meijers, M.J.M., van Hinsbergen, D.J.J., Dekkers, M.J., Altıner, D., Kaymakc1, N. \& Langereis, C.G., 2011. Pervasive Palaeogene remagnetization of the central Taurides fold-and-thrust belt (southern Turkey) and implications for rotations in the Isparta Angle, Geophys. J. Int., 184, 1090-1112.

Mochales, T., Casas, A.M., Pueyo, E.L. \& Barnolas, A., 2012. Rotational velocity for oblique structures (Boltaña anticline, Southern Pyrenees), $J$. Struct. Geol., 35, 2-16.

Muñoz, J.-A., Beamud, E., Fernández, O., Arbués, P., Dinarès-Turell, J. \& Poblet, J., 2013. The Ainsa Fold and thrust oblique zone of the central Pyrenees: kinematics of a curved contractional system from paleomagnetic and structural data, Tectonics, 32, 1142-1175.

Oliva-Urcia, B. \& Pueyo, E.L., 2019. Paleomagnetism in structural geology and tectonics (review chapter), in Teaching Methodologies in Structural Geology and Tectonics, pp. 55-121, ed. Mukherjee, S., Springer, ISBN: 978-981-13-2781-0, doi: 10.1007/978-981-13-2781-0.

Pastor-Galán, D., Mulchrone, K.F., Koymans, M. R., van Hinsbergen, D. J. \& Langereis, C. G., 2017. Bootstrapped total least squares orocline test: a robust method to quantify vertical-axis rotation patterns in orogens, with examples from the Cantabrian and Aegean oroclines, Lithosphere, 9(3), 499-511.

Pueyo, E.L., Pocoví, A., Parés, J.M., Millán, H. \& Larrasoana, J.C., 2003. Thrust ramp geometry and spurious rotations of paleomagnetic vectors, Stud. Geophys. Geod., 47, 331-357.

Pueyo, E.L., Pocoví, A., Millán, H. \& Sussman, A.J., 2004. Map-view models for correcting and calculating shortening estimates in rotated thrust fronts using paleomagnetic data, Geol. Soc. Am., 383, $1-15$.

Pueyo, E.L., Sussman, A.J., Oliva-Urcia, B. \& Cifelli, F., 2016. Palaeomagnetism in fold and thrust belts: use with caution, Geol. Soc. Lond., Spec. Publ., 425, 259-276.

Pueyo, E.L. et al., 2017. Proceedings de la Reunión de la Comisión de Paleomagnetismo de la SGE- MAGIBER-X (Valle del Grío), ISBN: 97884-16723-40-9, pp. 94-99.

Pueyo, E.L. et al. 2020 (in press). The geometry and kinematics of the Southwestern termination of the Pyrenees: a field guide to the Sto. Domingo anticline, in Structural Geology \& Tectonics Field Guidebook, ed.Mukherjee, S., Springer.

Ramón, M.J., 2013. Flexural Unfolding of Complex Geometries in Fold and Thrust Belts Using Paleomagnetic Vectors, Unpublished PhD thesis, Universidad de Zaragoza, 228 pp. https://zaguan.unizar.es/record/11750/ usage $? \mathrm{ln}=$ es.

Ramón, M.J., Pueyo, E.L., Oliva-Urcia, B. \& Larrasoaña, J.C., 2017. Virtual directions in paleomagnetism: a global and rapid approach to evaluate the NRM Components, Front. Earth Sci., 5, 1-14.

Ramsay, J.G. \& Huber, M.I., 1987. The Techniques of Modern Structural Geology. Volume 2: Folds and Fractures, Academic Press.

Rodríguez-Pintó, A. et al. 2016. Rotational kinematics of a curved fold: the Balzes anticline (Southern Pyrenees), Tectonophysics, 677-678, 171189.

Rodriguez-Pintó, A., Pueyo, E.L, Barnolas, A., Pocoví, A., Oliva-Urcia, B. \& Ramón, M.J., 2013. Overlapped paleomagnetic vectors and fold geometry: a case study in the Balzes anticline (Southern Pyrenees), Phys. Earth planet. Inter., 215, 43-57.

Shipunov, S.V., 1997. Synfolding magnetization: detection, testing and geological applications, Geophys. J. Int., 130, 405-410.

Simón, J.L., 2004. Superposed buckle folding in the eastern Iberian Chain, Spain, J. Struct. Geol., 26, 1447-1464.

Smith, B. et al. 2006. Relative importance of the Hercynian and postJurassic tectonic phases in the Saharan platform: a palaeomagnetic study of Jurassic sills in the Reggane Basin (Algeria), Geophys. J. Int., 167, 380-396.
Soto, R., Casas-Sainz, A.M. \& Villalain, J.J., 2011. Widespread Cretaceous inversion event in northern Spain: evidence from subsurface and palaeomagnetic data, J. Geol. Soc. Lond., 168, 899-912.

Soto, R., Casas-Sainz, A.M. \& Pueyo, E.L., 2006. Along-strike variation of orogenic wedges associated with vertical axis rotations, J. geophys. Res., 111, B10402, doi:10.1029/2005JB004201.

Stamatakos, J. \& Kodama, K.P., 1991. Flexural flow folding and the paleomagnetic fold test: an example of strain reorientation of remanence in the Mauch Chunk Formation, Tectonics, 10, 807-819.

Surmont, J., Sandulescu, M. \& Bordea, S., 1990. Mise en évidence dúne réaimantation fini crétacée des séries mésozoïques de l'unité de Bihor (Monts Apuseni, Roumanie) et de sa rotation horarie ultériore, Comptes Rendus L Acad. Des Sci. Paris, 310, 213-219. Retrieved from http://link inghub.elsevier.com/retrieve/pii/S1631073X12001926.

Sussman, A.J., Butler, R.F., Dinarès-Turell, J. \& Vergés, J., 2004. Verticalaxis rotation of a foreland fold and implications for orogenic curvature: an example from the Southern Pyrenees, Spain, Earth planet. Sci. Lett., 218(3-4), 435-449.

Sussman, A.J., Pueyo, E.L., Chase, C.G., Mitra, G. \& Weil, A.B., 2012. The impact of vertical-axis rotations on shortening estimates, Lithosphere, $\mathbf{4}$, 383-394.

Tauxe, L. et al. 2016. PmagPy: Software package for paleomagnetic data analysis and a bridge to the Magnetics Information Consortium (MagIC) Database, Geochem. Geophys. Geosyst., 17(6), 2450-2463.

Torres-López, S., Villalaín, J.J., Casas, A.M., El Ouardi, H., Moussaid, B. \& Ruiz-Martínez, V.C., 2014. Widespread Cretaceous secondary magnetization in the High Atlas (Morocco). A common origin for the Cretaceous remagnetizations in the western Tethys?, J. Geol. Soc. London., 171, 673687.

Torres-López, S., Casas, A.M., Villalaín, J.J., El Ouardi, H. \& Moussaid, B., 2016. Pre-Cenomanian vs Cenozoic folding in the High Atlas revealed by palaeomagnetic data, Terra Nov., 28, 110-119.

Torres-López, S., Casas, A.M., Villalaín, J.J., Moussaid, B., Ruiz Martínez, V.C. \& El-Ouardi, H., 2018. Evolution of the ridges of Midelt-Errachidia section in the high atlas revealed by paleomagnetic data, Tectonics, $\mathbf{3 7}$, 3018-3040.

Van der Pluijm, B.A., 1987. Grain-scale deformation and the fold test evaluation of syn-folding remagnetization, Geophys. Res. Lett., 14, 155157

Van der Voo, R. \& Torsvik, T.H., 2012. The history of remagnetization of sedimentary rocks: deceptions, developments and discoveries, Geol. Soc. Lond., Spec. Publ., 371, 23-53.

Villalaín, J.J., Osete, M.L., Vegas, R. \& García-Dueñas, V., 1992. Evidencia de una reimanación terciaria en la Béticas Occidentales. Implicaciones tectónicas, Física de la Tierra, 4, 165-184.

Villalaín, J.J., Fernández-González, G., Casas, A.M. \& Gil-Imaz, A., 2003. Evidence of a Cretaceous remagnetization in the Cameros Basin (North Spain): implications for basin geometry, Tectonophysics, 377, 101-117.

Villalaín, J.J., Casas-Sainz, A.M. \& Soto, R., 2016. Reconstruction of inverted sedimentary basins from syn-tectonic remagnetizations. A methodological proposal, Geol. Soc. Lond., Spec. Publ., 425, 233-246.

Waldhör, M., 1999. The Small-Circle Reconstruction in Palaeomagnetism and its Application to Palaeomagnetic Data from the Pamirs, Tübingen University.

Waldhör, M. \& Appel, E., 2006. Intersections of remanence small circles: new tools to improve data processing and interpretation in palaeomagnetism, Geophys. J. Int., 166, 33-45.

Fisher, R., 1953. Dispersion on a Sphere, Proc. R. Soc. A Math. Phys. Eng. Sci., 217, 295-305.

\section{SUPPORTING INFORMATION}

Supplementary data are available at $G J I$ online.

Fig. SM1.1. The relationship between the error in the palaeodip $(\delta)$ and the error in the reference calculation $(\varepsilon)$ depends on the differences between the apical angle of the SC (Ap) and the apical 
angle of the great circle (GC) that contains the expected and the calculated reference, which always is $90^{\circ}$.

Fig. SM2.1. VARs models for different inclinations of the remagnetization: (a) $15^{\circ}$, (b) $45^{\circ}$ and (c) $90^{\circ}$. Symbols as in Fig. 8 .

Fig. SM2.2. VARs models carried out with the original fixed remagnetization direction. Symbols as in Fig. 8.

Fig. SM3.1. dHARs models for different inclinations of the remagnetization: (a) $15^{\circ}$, (b) $45^{\circ}$ and (c) $90^{\circ}$. Symbols as in Fig. 9.

Fig. SM3.2. dHARs models carried out with the original fixed remagnetization direction. Symbols as in Fig. 9.

Please note: Oxford University Press is not responsible for the content or functionality of any supporting materials supplied by the authors. Any queries (other than missing material) should be directed to the corresponding author for the paper.

\section{APPENDIX A: PARAMETERS OF THE MATHEMATICAL MODELS (SECTION 3.3)}

1. Re-magnetization moment:

$$
\mathrm{S} 01\left(\mathrm{~s}_{1}, \mathrm{~d}_{0}\right)
$$

$\mathrm{S} 02\left(\mathrm{~s}_{2}, \mathrm{~d}_{0}\right)$

pmag0 $\left(\operatorname{dec}_{0}\right.$, inc $\left._{0}\right)$ where inc ${ }_{0}=\tau$

Where the primary non-coaxiality is $\Omega=\mathrm{s}_{2}-\mathrm{s}_{1}$ and the obliquity is the $\sigma=\mathrm{s}_{1}-\operatorname{dec}_{0}$

$$
\begin{aligned}
& \text { 2. Second stage of folding (additional dip } \sigma) \text { : } \\
& \text { S01 }\left(\mathrm{s}_{1}, \mathrm{~d}_{1}\right) ; \mathrm{d}_{1}=\mathrm{d}_{0}+\sigma \\
& \mathrm{S} 02\left(\mathrm{~s}_{1}, \mathrm{~d}_{2}\right) ; \mathrm{d}_{2}=\mathrm{d}_{0}+\sigma \\
& \text { pmag } 1\left(\mathrm{dec}_{1}, \text { inc }_{1}\right)=\mathrm{R} 1 \cdot \operatorname{pmag} 0 \\
& \text { pmag2 }\left(\mathrm{dec}_{2}, \text { inc }_{2}\right)=\mathrm{R} 2 \cdot \operatorname{pmag} 0
\end{aligned}
$$

Where $\mathrm{R} 1$ and $\mathrm{R} 2$ are values of the rotation matrix described in the Appendix B.

$\mathrm{R} 1$ : rotation matrix with horizontal axis $=[\mathrm{s} 1,0]$ and magnitude $=\sigma$

$\mathrm{R} 2$ : rotation matrix with horizontal axis $=[\mathrm{s} 2,0]$ and magnitude $=\sigma$

In this situation, the small circles (which equation is also described in the Appendix B) are:

$\mathrm{SC} 1$ : axis $=\left[\mathrm{s}_{1}, 0\right]$ and magnitude $=\cos ^{-1}\left[\cos \left(\mathrm{s}_{1}-\operatorname{dec}_{1}\right)\right.$. $\cos \left(\right.$ inc $\left.\left._{1}\right)\right]$

$\mathrm{SC} 2$ : axis $=\left[\mathrm{s}_{2}, 0\right]$ and magnitude $=\cos ^{-1}\left[\cos \left(\mathrm{s}_{2}-\operatorname{dec}_{2}\right)\right.$. $\cos \left(\right.$ inc $\left.\left._{2}\right)\right]$

3. Additional $\operatorname{VAR}(\beta)$ in one of the limbs (in this case $\mathrm{S} 02$ ):
R_VAR: rotation matrix with vertical axis $=\left[0,90^{\circ}\right]$ and magnitude $=\beta$

pmag $2 *\left(\operatorname{dec}_{2 *}, \operatorname{inc}_{2 *}\right)=\mathrm{R} \_$VAR $\cdot$ pmag2; $\operatorname{dec}_{2 *}=\operatorname{dec}_{2}+\beta$, inc $_{2 *}$ $=$ inc $_{2}$

$\mathrm{S} 02 *\left(\mathrm{~s}_{2 *}, \mathrm{~d}_{2 *}\right)=\mathrm{R}_{-}$VAR $\cdot \mathrm{S} 02 ; \mathrm{s}_{2 *}=\mathrm{s}_{2}+\beta ; \mathrm{d}_{2 *}=\mathrm{d}_{2}$

$\mathrm{SC} 2 *$ : axis $=\left[\mathrm{s}_{2 *}, 0\right]$ and magnitude $=\cos ^{-1}\left[\cos \left(\mathrm{s}_{2 *}-\operatorname{dec}_{2 *}\right)\right.$. $\cos \left(\right.$ inc $\left.\left._{2 *}\right)\right]=\cos ^{-1}\left[\cos \left(\mathrm{s}_{2}-\mathrm{dec}_{2}\right) \cdot \cos \left(\mathrm{inc}_{2}\right)\right]$ which is SC2 magnitude.

\section{APPENDIX B}

Small Circle (SC) equation:

$\mathrm{a} \cdot \mathrm{x}+\mathrm{b} \cdot \mathrm{y}=\mathrm{d}$ where $\mathrm{a}$ and $\mathrm{b}$ are the normal vector of the SC in Cartesian coordinates and $\mathrm{d}$ the distance between SC and origin which is the cosine of the magnitude.

$\mathrm{a}=\cos ($ strike $), \mathrm{b}=\sin ($ strike $), \mathrm{d}=\cos ($ strike-dec $) \cdot \cos (\mathrm{inc})$

$\mathrm{x}^{2}+\mathrm{y}^{2}+\mathrm{z}^{2}=1$

$\underline{\mathrm{R}}$ : Rotation Matrix around axis $=[\mathrm{x}, \mathrm{y}, \mathrm{z}]$ a magnitude $\mathrm{A}$

$R=\left(\begin{array}{lll}x \cdot x \cdot(1-\cos A)+\cos A & x \cdot y \cdot(1-\cos A)-z \cdot \sin A & x \cdot z \cdot(1-\cos A)+y \cdot \sin A \\ x \cdot y \cdot(1-\cos A)+z \cdot \sin A & y \cdot y \cdot(1-\cos A)-\cos A & y \cdot z \cdot(1-\cos A)+x \cdot \sin A \\ x \cdot z \cdot(1-\cos A)-y \cdot \sin A & y \cdot z \cdot(1-\cos A)+x \cdot \sin A & z \cdot z \cdot(1-\cos A)+y \cdot \cos A\end{array}\right)$

Coordinate system:

$$
\begin{aligned}
& \text { declination } \rightarrow \alpha=a \tan (y / x) \\
& \text { inclination } \rightarrow \tau=a \tan \left(z / \sqrt{x^{2}+y^{2}}\right.
\end{aligned}
$$

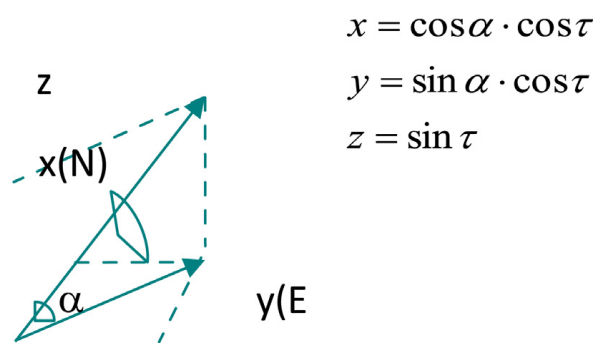

\section{APPENDIX C}

Errors derived from the SCI calculation using different approaches. (See section 5.1) 


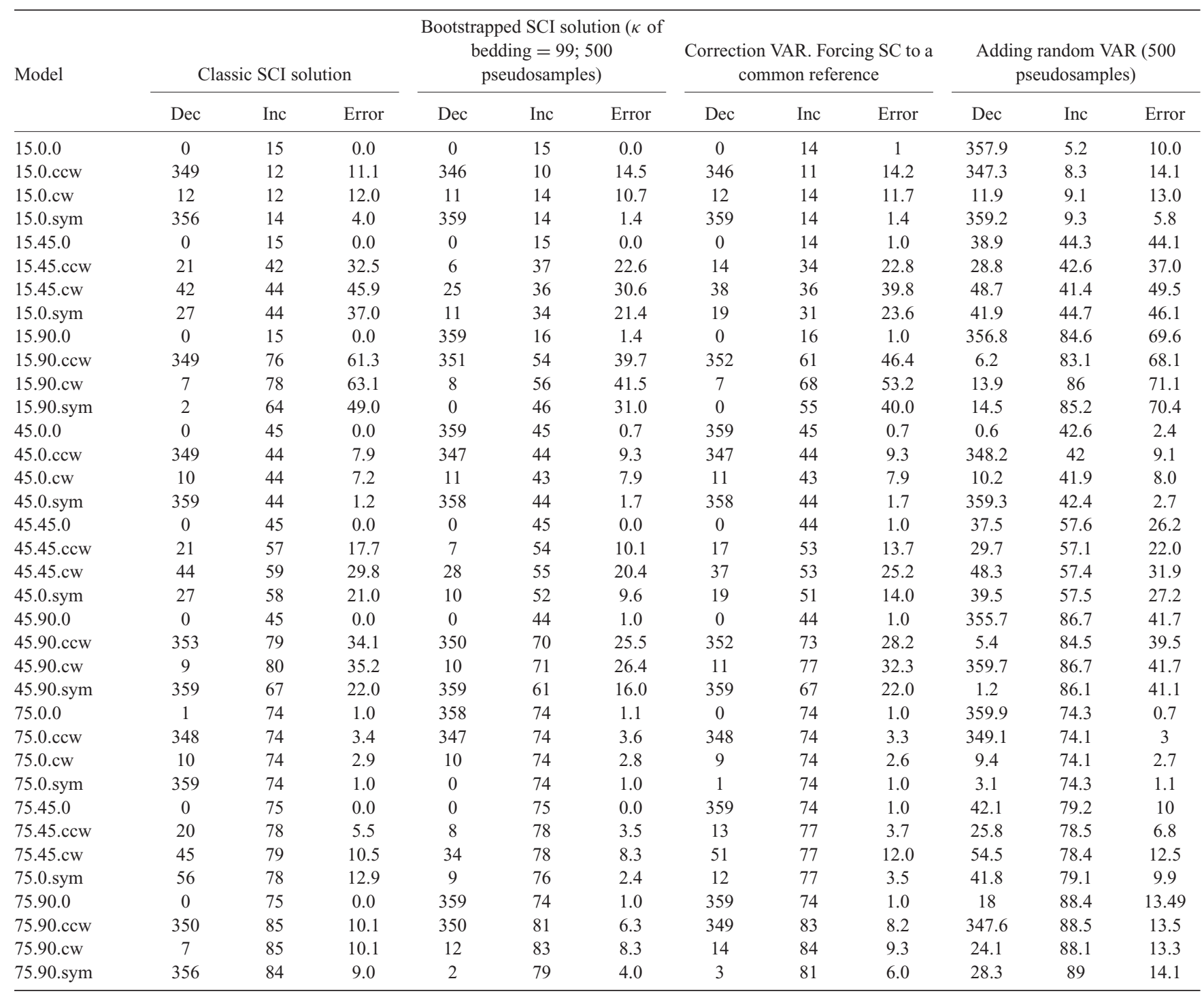

